This item was submitted to Loughborough's Research Repository by the author.

Items in Figshare are protected by copyright, with all rights reserved, unless otherwise indicated.

\title{
Unpacking multimethodology: impacts of a community development intervention
}

PLEASE CITE THE PUBLISHED VERSION

http://dx.doi.org/10.1016/j.ejor.2016.02.044

PUBLISHER

(C) Elsevier

VERSION

AM (Accepted Manuscript)

\section{PUBLISHER STATEMENT}

This work is made available according to the conditions of the Creative Commons Attribution-NonCommercialNoDerivatives 4.0 International (CC BY-NC-ND 4.0) licence. Full details of this licence are available at: https://creativecommons.org/licenses/by-nc-nd/4.0/

\section{LICENCE}

CC BY-NC-ND 4.0

\section{REPOSITORY RECORD}

Henao, Felipe, and Alberto Franco. 2016. "Unpacking Multimethodology: Impacts of a Community Development Intervention”. Loughborough University. https://hdl.handle.net/2134/20767. 


\title{
Unpacking multimethodology: Impacts of a community development intervention
}

\author{
Felipe Henao ${ }^{\mathrm{a}^{* 1}}$, L. Alberto Franco ${ }^{\mathrm{b}}$ \\ ${ }^{a}$ Universidad Icesi, Facultad de Ciencias Administrativas y Económicas, Departamento de Gestión \\ Organizacional, Calle 18 No. 122 -135, Cali, Colombia. \\ ${ }^{b}$ School of Business and Economics, Loughborough University, Leicestershire LE11 3TU, UK
}

\begin{abstract}
Multimethodology interventions are being increasingly employed by operational researchers to cope with the complexity of real-world problems. In keeping with recent calls for more research into the 'realised' impacts of multimethodology, we present a detailed account of an intervention to support the planning of business ideas by a management team working in a community development context. Drawing on the rich steam of data gathered during the intervention, we identify a range of cognitive, task and relational impacts experienced by the management team during the intervention. These impacts are the basis for developing a process model that accounts for the personal, social and material changes reported by those involved in the intervention. The model explains how the intervention's analytic and relational capabilities incentivise the interplay of participants' decision making efforts and integrative behaviours underpinning reported intervention impacts and change. Our findings add much needed empirical case material to enrich further our understanding of the realised impacts of operational research interventions in general, and of multimethodology interventions in particular.
\end{abstract}

Keywords: decision processes; problem structuring; multimethodology; intervention; impacts.

\section{Introduction}

Since the publication of Mingers and Brocklesby's (1997) seminal paper, there has been an increasing interest in exploiting the opportunities offered by mixing operational research methodologies, methods and tools to increase our ability to tackle the complexity of realworld problems situations. To date, attention has been mostly paid to debating the philosophical and theoretical dimensions of multimethodology work, as well as sharing the lessons gained from the application of different forms of multimethodology designs in the field. The former is concerned with the feasibility of mixing methodologies from different paradigms -namely, the commensurability versus incommensurability debate - (e.g. Eden, Ackermann, Bryson, Richardson, \& Andersen, 2009; Jackson, 2009; Kotiadis \& Mingers, 2006; Mingers, 1997; Zhu, 2011); whereas the latter relates to the different ways in which specific methodologies, methods and tools are actually mixed in organisational interventions (Brown, Cooper, \& Pidd, 2006; Ferreira, 2013; Franco \& Lord, 2011; Gondal, 2004; Ormerod, 2001; Pollack, 2009; Small \& Wainwright, 2014; Sørensen, Vidal, \& Engstrom, 2004; Tako \& Kotiadis, 2015; Williams, Ackermann, \& Eden, 2003; Yearworth \& White, 2013).

A recent review by Howick and Ackermann (2011) showed that in spite of significant activity in the field, there is still little empirically-informed understanding of the realised impacts of multimethodology interventions. To address this gap, we present a detailed account of our work with the management team of an organisation operating in a community development context. The team was tasked with planning business ideas intended to support the

\footnotetext{
${ }^{1 \text { *} C o r r e s p o n d i n g ~ a u t h o r: ~ T e l: ~+~ 57-~} 2$-5552334 ext 8208; fax: +57 - 2 - 5551441; email address: jfhenao@icesi.edu.co
} 
development of a disadvantaged community in Colombia. It is our empirical investigation of the intervention impacts reported by the management team that forms the basis of the present paper. Our aim is to share empirically-informed insights into the supporting mechanisms behind the attainment of multimethodology intervention impacts, with particular emphasis on process-related impacts.

In what follows we first briefly discuss the theoretical rationale underlying multimethodology practice and its claimed benefits. Details of our intervention are provided next, which include a description of the intervention context, a justification for our choice of intervention design, an outline of expected intervention impacts, and a detailed account of the actual deployment of the intervention and its outcomes. Our methodological approach to evaluating the intervention is then explained, which involved a systematic iterative-inductive analysis of the data generated during the intervention. Our examination enabled us to develop a process model that advances understanding of multimethodology intervention impacts by unpacking its effects on the interplay of decision making and relational engagement efforts associated with changes in the personal, social, and ultimately material worlds of those involved. We finish the paper by discussing and summarising our main arguments, and drawing together our principal conclusions.

\section{The case for multimethodology}

Although several arguments have been used by operational researchers to advocate multimethodology practice, we will focus here on the two main arguments that seem to best summarize the debate. The first one states that the use of only one methodology is not enough to tackle all the complexity associated with real-world problem situations (Bennett, 1985; Jackson \& Keys, 1984; Mingers, 2000; Mingers \& Brocklesby, 1997). This view comes from the recognition that individual methodologies exhibit different strengths and weaknesses when dealing with different aspects of a problem situation that is complex, namely, material, personal and social aspects (Mingers \& Brocklesby, 1997). Material aspects are features of a situation that are perceived as independent of individuals and which can be created, shaped and transformed through their actions like physical resources, time, objects, entities, and so forth; personal aspects refer to an individual's knowledge, emotions, values and beliefs about a situation of concern; and social aspects refer to the interactions between individuals involved in the problem situation that may take place through language, norms and practices.

For example, optimization and simulation approaches are commonly thought of as appropriate for representing the material aspects of a problem situation, because they are able to find better ways to allocate physical resources and the models built can be easily transferred and employed into other contexts. Problem structuring methods (PSMs) (Mingers \& Rosenhead, 2004; Rosenhead \& Mingers, 2001), on the other hand, are considered more suited for addressing the personal and social aspects of problem situations. To illustrate, SODA (Ackermann \& Eden, 2010) has strengths in representing individuals' beliefs about a problem and in gaining their commitment to action (personal dimension); whereas SSM (Checkland \& Poulter, 2006) has some techniques (i.e. Analysis 1, 2 and 3) for appreciating stakeholders, culture and power relations associated with a particular problem context (social dimension). Consequently, combining methodologies (or parts thereof) to tackle a complex situation is considered to be, in principle, more effective than using single-methodology approaches (Mingers \& Brocklesby, 1997). 
The second argument states that individual methodologies may not be similarly equipped to support the different stages involved in an intervention (Mingers, 2000; Ormerod, 1998, 2001). Indeed, several authors have compared the strengths and weaknesses of different methodologies against particular conceptualizations of intervention stages. For example, scholars such as Franco and Lord (2011) and Belton et al (1997) argue that qualitative problem structuring methodologies and quantitative multi-criteria decision analysis approaches differ in their relative ability to support the divergent and convergent work stages of an intervention, respectively. More generally, Mingers and Brocklesby (1997) discuss the strengths and weaknesses of different methodologies in relation to the appreciation, analysis, assessment and action stages of an intervention. They posit that by combining methodologies (or parts thereof) within a single intervention, their support capabilities could complement each other and bring together their individual benefits (or even create more benefits) to the intervention. Furthermore, the relative weaknesses of some methodologies could be overcome with the relative strengths of others, leading to more effective interventions (Howick \& Ackermann, 2011; Pidd, 2004).

To summarize, the implied benefits of combining methodologies seem to relate to both the multi-dimensional nature of the problem under study, and the support capability provided by particular methodologies within each work stage of an intervention. In other words, the use of multimethodology is assumed to enable those involved to better capture the complexity of the problem situation of concern, as well as deploy the most appropriate methodology to complete each intervention work stage. It is important to note that these expected benefits have been articulated in broad theoretical terms and have not been substantiated by in-depth empirical studies. Of course, there is no denying that there is an increasing literature of the use of multimethodology in practice. However, with some notable exceptions (Franco \& Lord, 2011; White, 2009), there is a lack of empirically-informed accounts showing how these expected benefits are realised in practice, and what underpinning mechanisms are behind their attainment (cf. Howick \& Ackermann, 2011). The present paper is our attempt to unpack these important, yet under researched, empirical aspects of multimethodology practice.

\section{The multimethodology intervention}

In order to examine the impacts of any (multimethodology) intervention, we first need to articulate the main difficulties embedded within the problem situation of concern (i.e. the intervention context), and then explore how individual methodologies, methods or tools could help in tackling them, and with what expected effects. This analysis can then inform the empirical exploration of whether these expected impacts materialised or not due to the intervention. The next sections discuss these issues in more detail for the case of a multimethodology intervention deployed in a community development context. The intervention described below took place within the context of an overarching programme aimed at developing different socio-economic initiatives to improve the precarious conditions of a group of families living in Moravia, a shantytown located in the northeast part of Medellin, which is the second largest city of Colombia with over 3 million people. We start by discussing the context of the intervention at the time of our involvement. Next we provide the rationale underpinning our choice of intervention design. Finally, we describe how the intervention was conducted.

\subsection{Intervention context}


Moravia is a highly deprived community of approximately 45,000 people who live on an area that used to be a rubbish dump (see Figure 1). Moravia's inhabitants are mostly displaced people, victims of the armed conflict that has taken place between the government forces and the paramilitary and guerrilla groups for the past 40 years. Shantytowns like Moravia have a multi-cultural and multi-ethnic profile, and families usually live in very confined dwellings or hovels that lack the basic public services such as electricity, drinkable water, and sewer systems.

\section{PLACE FIGURE 1 ABOUT HERE}

In 2006, due to the precarious living conditions and the rubbish that lies beneath the town, the local authority declared the area in a state of emergency and demanded to relocate around 1900 families. This relocation initiative, known as the Moravia Project (or 'Proyecto Moravia' in Spanish), was intended to provide low-cost housing outside the affected area and socio-economic support to ensure the long-term sustainability of the families in the new location. Multiple organizations and institutions were involved within this project. One of these was a local non-governmental organization called Antioquia Presente (AP), whose objectives were to: (1) assist members of the relocated families to find jobs; and, (2) develop business ideas that could improve the household economy of these families. Our client was a 12-member team, referred to as the APT hereafter, set up to achieve these objectives and comprised of six managers and six social workers.

Our role as operational researchers was to assist the APT in developing innovative, feasible, and financially and socially sustainable new business ideas. This was a challenging undertaking for several reasons. First, the APT had to complete the task without the input of the Moravian community. This was because community members had a bad experience of working with organisations like the AP in the past, and hence were reluctant to get involved. Second, the APT had only partial experience in formal business planning tasks, with some members having little or no experience at all. Third, differences in domain-specific expertise (i.e. management versus social work) meant that APT members had conflicting views about how to undertake their planning task. Furthermore, there were tensions between some social workers and the APT leader, which were due to a perceived lack of consistency and objectivity in decision making practices within the APT. Finally, because planning was essentially a management activity, there was a sense that social workers felt a little disadvantaged when it came to bidding for funding their proposals for business ideas. Overall these issues represented a complex context for the intervention. Table 1 below provides a summary of the intervention context which, in line with Mingers and Brocklesby's (1997) conceptualisation of problem situations, is organised across its material, personal and social dimensions.

\section{PLACE TABLE 1 ABOUT HERE}

\subsection{Intervention design}


Despite the plethora of intervention design frameworks available (e.g. Bennett, 1985; Cropper, 1990; Flood \& Jackson, 1991; Midgley, 1997; Ormerod, 2008), it is unlikely that a prescribed 'best way' of combining methods exists because intervention design is not an exact science. Nonetheless, it is helpful to be explicit about the design framework chosen so that the expected impacts of the intervention can be traced. To this end, we drew upon the work of Mingers (2000, 2001, 2003), who suggests to design multimethodology interventions by first considering the four generic activities that are typical of any planned intervention: appreciation of the situation as experienced by those involved; analysis of the underlying structure/constraints generating the situation as experience; assessment of the ways in which the situation could be alleviated or changed; and action to bring about change.

We thus used a range of facilitated modelling approaches (Franco \& Montibeller, 2010) to support these intervention activities, which were undertaken in a 'linear' fashion (Pollack, 2009). First, we chose field visits combined with cognitive mapping interviews and a facilitated group causal mapping workshop (Ackermann \& Eden, 2010; Bryson, Ackermann, Eden, \& Finn, 2004) to support appreciation activities. Field visits would enable us to get acquainted with issues affecting the physical circumstances of the Moravian community. Cognitive mapping interviews would allow us to surface the perspectives of APT members regarding the Moravian situation and the intervention. In addition, these interviews would give us (indirect) access to how APT members view their working practices and social relations. Finally, the group causal mapping workshop would afford APT members with the opportunity to hear each other's views. To carry out each mapping approach, we planned using the Decision Explorer software (www.banxia.com),

An increased familiarity with the Moravian context, together with the identification of APT members' perspectives as captured by cognitive mapping fed directly into analysis activities. Indeed, the analytic routines embedded within the Decision Explorer would allow for the causal structures of the different perspectives represented in the cognitive/causal maps to be easily organised and investigated. These analyses would also enable us to (indirectly) highlight certain issues associated with working practices and social relations among APT members. The group causal mapping workshop would also enable us to perform qualitative assessments of priority areas within which potentially useful business ideas could be developed. These candidate business ideas would then provide the starting point of the subsequent analysis activities. We chose to support these activities with elements of soft systems methodology (Checkland \& Poulter, 2006; Wilson, 2001), and a facilitated decision conference (Phillips, 2007). The former comprised the use of CATWOE and activity systems modelling to 'flesh out' the detail of a selected set of candidate business ideas; the latter involved the conduct of a multi-criteria decision analysis (Belton \& Stewart, 2002) using a decision conferencing format (Phillips, 2007) to quantitatively evaluate the business ideas against agreed criteria. Building the evaluation model and conducting the multi-criteria analysis would be supported by the HiView software (www.catalyze.co.uk). Finally, action to bring about change activities would focus on reviewing all the outputs produced in the previous activities, and reaching agreements for action. Specifically, (1) the priority areas highlighted in the group causal map, together with the evaluated business would be discussed; and (2) an action plan to guide implementation would be agreed by APT members.

It is worth noting that the selection of methods typically depends on their perceived usefulness to support a task within an intervention stage. However, there may be a range of methods that could be used to support a particular intervention task. For example, structuring 
decision options could be supported by causal mapping or the techniques of the Strategic Choice Approach. In such cases, the choice of method is typically influenced by the particular set of modelling skills or 'competences' that the OR analyst has and is able to demonstrate to the client (Keys, 2006; Kotiadis \& Mingers, 2006; Ormerod, 2008, 2014). In our case, our knowledge of and experience with problem structuring and decision analysis methods (e.g. Franco \& Lord, 2011; Henao, Cherni, Jaramillo, \& Dyner, 2012; Hindle \& Franco, 2009) meant that we had the requisite level of competency for mixing these methods in practice and, therefore, our particular choice of methods seemed both natural and useful for the intervention at hand.

Table 2 provides an overview of our intervention design. Note that the table also subdivides the intervention activities according to whether they are intended to address the material, personal or social dimensions of the intervention context discussed in the previous section. As can be seen in Table 2, by using a combination of approaches that complemented the strengths and weaknesses of each other considered individually, our design was intended to deploy an intervention as robust and as comprehensive as possible. The last column in Table 2 shows the intervention impacts expected across the material, individual and social domains. Note that although we did not plan any particular action to bring about change in working practices and social relations within the APT, we expected that at least some of our intervention activities (e.g. group causal mapping) would contribute towards improvements in this area. Also, our expected impacts have exclusively focused on the APT (our client) rather than the Moravia community. Whilst the impact of our intervention (through the implemented business ideas) on the Moravian community is obviously important, this evaluation would require a longer evaluation timeframe that is out of the scope of this paper.

\section{PLACE TABLE 2 ABOUT HERE}

\subsection{Intervention implementation}

As mentioned earlier, the appreciation phase was about making sense of the Moravian situation, which entailed exploring the problem of concern and articulating the main issues there. After visiting the site to appreciate the physical circumstances affecting the Moravian community, we then captured the perceptions that each APT member held about the situation in Moravia. APT members were individually interviewed by the first author following Bryson's et al. (2004) interview protocol, and then, from each interview a cognitive map was elaborated. Maps were initially written on paper and then electronically reproduced using the Decision Explorer software to facilitate their analysis. Each interviewee received, afterwards, an electronic copy of his/her map for validation. They were asked to corroborate whether the maps reflected what was discussed during the interviews and provide us feedback otherwise. Few comments were received by then, probably because maps were in fact constructed in front of the interviewees and with their participation.

After that, all the individual maps were combined and merged together in order to produce a single group map. Ten emergent clusters representing different themes that concerned APT members were highlighted in the group map: (1) a cluster with ideas of possible new businesses; (2) a cluster about the technicalities required in order to make the business ideas happen; (3) a cluster about budgeting and funding issues; (4) a cluster with ideas on how to motivate the community to get involved; (5) a cluster with ideas on how to speed-up and 
make more efficient the work of the APT itself; and finally, five clusters (6)-(10) regarding the potential impacts of the business ideas on different community dimensions - natural, social, human, physical and financial. The first five clusters emerged freely from structuring the content of the conversations by following the logic of the problem. Questions such as: 'what business ideas do you have in mind?' and 'what would be required to make them happen?' were asked, among others, during the interviews. The last five clusters were based on the sustainable likelihoods framework and developed top down (e.g. Henao et al., 2012).

The group map was presented at a workshop facilitated by the first author. Figure 2 shows an extract of the group's map. During the workshop, the facilitator helped APT members to explore and further elaborate the different clusters, and also identify and agree on the key areas within which the development of business ideas would be useful.

\section{PLACE FIGURE 2 ABOUT HERE}

The most promising business ideas identified in the group map were further elaborated in a second workshop, also facilitated by the first author. In this workshop, methods and tools from Soft Systems Methodology (SSM) (e.g. rich pictures, CATWOE, conceptual modelling) were employed to help the APT define the business ideas in more operational terms. In preparation for this task, the APT was asked to address, for each business idea, a set of specific questions that included a range of aspects such as: the type of products/services that would be offered; the nature of the business model; the resources needed; and who should be involved. Some of these questions were triggered by the group mapping activity described earlier. Used in this way, the SSM methods and tools provided a structured process to designing decision options (cf. Checkland \& Poulter, 2006; Checkland \& Scholes, 1990). The workshop started by training APT members on how to use SSM methods and tools in the way described earlier. Next, sub-groups were formed to work independently during the workshop to develop different business ideas. Finally, the sub-groups presented their business ideas in plenary. They were trained to use SSM, not only so they would be able to work independently in sub-groups during the workshop, but also be able to plan further business ideas after the workshop. It is worth noting that the APT codified our approach to operationalize business ideas in the form of a guideline document for future use. They expressed their intention to replicate the approach when working with members of the Moravian community at a later stage (see Section 5.1). Figure 3 shows the application of SSM methods and tools to operationalize a candidate business idea about recycling paper and carton-based materials to produce parts for housing roof construction.

\section{PLACE FIGURE 3 ABOUT HERE}

The first author facilitated a third workshop whose purpose was to discuss ways of assessing the potential benefits of the business ideas articulated in the second workshop. Specifically, the workshop task involved the exploration of relevant objectives and associated criteria that could inform an evaluation of candidate business ideas using multiple-criteria decision analysis (Belton \& Stewart, 2002). This proved a challenging task since reaching an agreement about how to perform the assessment, as well as knowing what kind of information would be available to perform the analysis, was not straightforward. The 
Please cite this article as:

Henao, F., \& Franco, L. A. Unpacking multimethodology: Impacts of a community development intervention.

European Journal of Operational Research (2016) http://dx.doi.org/10.1016/j.ejor.2016.02.044

facilitator brought the group map to the workshop and used it to highlight candidate objectives for the evaluation.

After the workshop, two separate multi-criteria evaluation models were developed that were informed by the workshop discussions. The first model was built to evaluate a set of small businesses, each to be run by a single family from the community (14 small businesses in total); the second model was built to evaluate a set of medium-sized businesses, each to be run by a group of families from the community (6 medium businesses in total). The models were built using the HiView software, and data needed to populate them was collected over a period of 1-2 months.

Finally, the first author facilitated a fourth and final workshop that adopted a decision conferencing format (Phillips, 2007). In this workshop the APT reviewed the data, models and discussed the results in depth (see Figure 4). No decision was taken at this workshop, although the potential benefits of the different small and medium businesses considered became evident. Our engagement with the APT terminated after this workshop, and had lasted 9 months in total.

\section{PLACE FIGURE 4 ABOUT HERE}

\section{Evaluation methodology}

The previous sections provided details about our intervention rationale and its subsequent implementation within the APT context. In this section we describe the methodology we adopted to evaluate our intervention. We adopted a 'client-driven' perspective to evaluating the intervention, rather than an 'analyst-driven' perspective, as we wanted to understand how APT members made sense of their experience of using our multimethodology approach in their own terms. Consequently, we evaluated our intervention using grounded theory principles (Glaser \& Strauss, 1967; Strauss \& Corbin, 1998), which helped us develop a datadriven explanation of the intervention's impact. Grounded theory is particularly suited to research that seeks to understand the processes by which a group of individuals construct meaning out of their intersubjective experience, and thus is more likely to reveal the subtlety and richness of individual experiences associated with OR interventions (Eden, 1995).

\subsection{Data collection}

The primary source of data employed in the evaluation consisted of semi-structured interviews conducted with all APT members two months after the intervention, and then again with the APT coordinator 18 months after the intervention. The interviews lasted between 45 and 75 minutes, and were recorded and transcribed verbatim (approximately 170 single-spaced A4 pages). We conducted the interviews in Spanish, and followed a 'storytelling' approach (Czarniawska, 2004). This approach requires that interviewers ask broad questions without directing their interviewees. In this way, interviewees were able to express their experience and perceptions about the whole intervention more freely. Thus, for example, general questions such as "Tell me about your experience of the intervention?" very frequently prompted interviewees to talk about a particular workshop and the method(s) and tool(s) associated with it. We would then ensure that responses about all the other workshops were also discussed during the interview. In addition, our interview protocol included a range 
of questions about the APT, including aspects such as work climate, communication, and decision making. Our analysis (described below) focused on the interview data, but we also drew on our field observations and notes to supplement and clarify our analyses.

\subsection{Data coding and analysis}

We followed an iterative-inductive approach to data analysis (O'Reilly, 2005; Orton, 1997) that comprised the use of grounded theory principles (Glaser \& Strauss, 1967; Strauss \& Corbin, 1998) to cycle back and forth between theory and data. The analytical steps described below are presented in a linear fashion, although the actual analysis involved several iterations between these steps.

We started by undertaking an initial review of the empirical literature on multimethodology impacts (e.g. Franco \& Lord, 2011; Howick \& Ackermann, 2011; Montibeller, Franco, Lord, \& Iglesias, 2009). However, we did not want to adhere too closely to the extant literature and thus aimed to be continuously aware of the possibility of being influenced by pre-existing conceptualisations. This is consistent with the generally accepted view of the link between literature reviews and the development of 'categories' (see below) in research that uses grounded theory (e.g. Suddaby, 2006).

Next, we read all the interview transcripts to identify reported broad changes associated with the personal, social and material worlds of those involved in the intervention. We then looked for initial impact-related concepts (i.e. codes) that could explain these reported changes, and grouped them into first-order categories through a process of 'open coding' (Strauss \& Corbin, 1998). We focused on each piece of interview data and then worked across the interview dataset looking for similarities and differences. For this analytical step we used 'invivo’ codes (Locke, 2001; Strauss \& Corbin, 1998; van Maanen, 2002) whenever possible (i.e. terms adequate at the level of meaning of the interviewees), or a simple descriptive phrase when an in-vivo code was not available. We coded the data using Atlas.ti (http://www.atlasti.com), a qualitative data analysis software that enabled us to keep track of emerging categories. Doing so allowed for quick reference to similar concepts and their representative examples that could be collapsed into fewer categories and themes, as well as collections of examples that needed to be parsed into more fine grained categories. The entire process of data coding and analysis was conducted in Spanish, and the findings translated into English. The analysis was not challenging language-wise as the authors are both native speakers of Spanish.

Next, we searched for and identified relationships between and among first-order categories through a process of 'axial coding' (Strauss \& Corbin, 1998). This allowed us to collapse first-order categories into a smaller set of second-order categories. This process proceeded iteratively, moving among data, emerging patterns and the literature, until the data were refined into adequate conceptual themes (Eisenhardt, 2002). The product of our analysis was thus anchored both empirically in our data and theoretically in the literature. The secondorder categories (i.e. conceptual themes) that emerged from our data represented three distinct levels of intervention impact: cognitive, task and relational. Although conceptually distinct, the achievement of these impacts was intertwined in practice. These impact levels were then used as the basis for developing a process model of multimethodology intervention impact that will be presented in the discussion section. 
To ensure that our analysis was credible or 'trustworthy' (Lincoln \& Guba, 1985; Shah \& Corley, 2006), we adopted a process of 'peer debriefing' between ourselves. The first author had primarily responsibility for gathering and initially analysing the interview data. The second author adopted a more general orientation, e.g. noting areas requiring more data, playing 'devil's advocate' by offering alternative explanations for developing findings, and considering the data at a level beyond the details contained in the qualitative database. Both authors were involved in the actual data analysis so that the credibility of the findings would not rely solely on the interpretations of a single researcher. This meant that any disagreements were used as a basis for discussion about how to strengthen the codes and thus improve the credibility of the interpretations. In addition, we gave an independent coder, who was not part of the research reported in this paper, to sort a sample of 30 quotations into the first-order and second-order categories generated from the analysis. We provided this independent coder with definitions of the first and second-order categories. The average agreement level of the independent coder was $78 \%$ for the first-order categories, and $83 \%$ for the second-order categories, indicating an acceptable level of agreement. We believe that these results, together with the approach adopted, demonstrates the credibility of our analysis.

\section{Evaluation findings}

In this section, we first present a brief summary of the changes reported by APT members and attributed to the intervention. Next, we present the findings of the impacts underpinning these changes, which were derived from the inductive-iterative analysis discussed above. It is worth noting that during the data collection interviewees expressed a wide variety of views regarding the intervention. However, our findings are solely based on those assessments that were prevalent in all or most interviewees in order to maintain the credibility of our results. Due to space imitations we illustrate our findings below with only a small set of interviewee quotes.

\subsection{Personal, social and material changes}

Overall, there is evidence suggesting that the intervention achieved some changes in the personal, social and material worlds of those involved. Managers and social workers reported changes in the way they thought about both, their projects and the project planning task:

"For example: the internet idea, the video games idea, and the washing machine idea, got me thinking a lot. Well, what happened is that although I know some of these ideas, like the video games, are not the most appropriate from a social impact point of view, I could have sworn that from the economic side of things it was going to be the business of the century. To find out through the figures that for this idea to be the business of the century I had to invest so much time and money, and that it wasn't really worth it, for me that was a big surprise" (Social Worker SW5)

\footnotetext{
"We hadn't thought about the social impact of the business ideas. Personally I hadn't included any social impact in them, and what is lacking in all projects is precisely that social component. Up to that point there was only a technical and economical proposal. Up to that moment we hadn't thought about it, but I do see now the importance of the social part in this, as well as the environmental part” (Manager MG2)
}

In addition, both managers and social workers expressed the view that the intervention had also led to changes in their team's social practices. Specifically, the evidence suggests that social workers had become empowered in terms of having a voice during interactions with 
Please cite this article as:

Henao, F., \& Franco, L. A. Unpacking multimethodology: Impacts of a community development intervention.

European Journal of Operational Research (2016) http://dx.doi.org/10.1016/j.ejor.2016.02.044

APT managers, and also in terms of having acquired knowledge about how to conduct project planning tasks.

"At the beginning we weren't really taken into account. We were much undervalued. After the workshops the social started to be considered very important: the community itself expressed it and in fact they were more inclined towards the social themes rather than the economic ones and more relevance was given to social work. Now it is valued." (Social Worker SW3)

"Our group was split and SW1 and I ended up together. I used to see her as someone with less experience and who was moved around within the team any way they wanted. But I got to know her, her talent, her skills, so much that within the team I started to loosen the reins and saw the responsibilities she was acquiring, and that what she did she did very well." (Manager MG4)

"I thought it was quite interesting because you no longer feel scared to ask or argue with the managers when you don't agree with them. I think that strengthens you position, takes away myths... Not being scared to sit in front of a worksheet to see if a project is profitable or not. To be able to sit with a manager to do a rule of three to see if (a project) was working and see what result came out. That was very enriching because I felt I was doing math things, something I thought was really cool". (Social Worker SW5).

Not surprisingly, the intervention led to changes in the way the APT's (material) project planning practices were conducted during the intervention. Perhaps more importantly, there is also evidence of changes in subsequent project planning practices that APT members attributed to the intervention. We visited Moravia eighteen months after our engagement with the APT, and there we learned that some of the businesses we evaluated had been actually implemented. Four of the six medium-sized businesses we had considered were up and running; the other two had not been pursued due to lack of community involvement and support. In addition, two new medium-sized businesses had been implemented. Interestingly, we were informed that these business ideas were developed together with members of the community with the guidance of the SSM-based workshop protocol used during the intervention.

"And there were team members whose previous experiences or working methods did not enable them to relate with people from the community, even more so with a community such as this. So undoubtedly there were problems with team members who for example had always worked in a company or industry .....and when coming into contact with community people did not know how to do it: the local people did not understand them at all. [After the intervention] we put together a form that came out of the [SSM] work you did with Manager MG5, a business plan form. From that [SSM work] we came out with one form that people could fill in. In case they couldn't fill it in, because there are a lot of people who can't read or write, we were there for them. The managers of the team would go there to help community people to fill in their forms, their business proposal. We called it a 'business plan', but the term is rather ambitious, so I would say it is more a business proposal. So, once they would formulate that proposal, they would leave it with us then and there, because asking people to do it at home is a bit complicated, because they either don't do it or get someone else to do it for them. So, we like them to do at least the exercise of knowing and thinking; who am I going to sell it to? These are actually very basic and simple documents. But they help people to have a general vision of what they should take into account for a project." (Manager MG4) 
Please cite this article as:

Henao, F., \& Franco, L. A. Unpacking multimethodology: Impacts of a community development intervention.

European Journal of Operational Research (2016) http://dx.doi.org/10.1016/j.ejor.2016.02.044

So there is evidence that more medium-term changes to the (material) project planning practices of the APT had taken place. There was, however, little indication or evidence that the evaluation of these new business ideas had followed the multi-criteria approach used in our intervention. With regards to the small businesses, we were told that 160 business ideas had been implemented, but it was not possible to determine whether these included any of the original fourteen businesses considered during our intervention. As in the case of the new small businesses implemented, most of these had apparently been developed with community involvement and the guidance of the SSM-based protocol. Figure 5 shows pictures of four medium-sized businesses that we had the opportunity to visit at that time.

\section{PLACE FIGURE 5 ABOUT HERE}

Insofar as our efforts to help the APT resulted in the implementation of some of the business ideas explored during our involvement, the intervention might be described as successful. In the next section, we interrogate our interview data further in order to unpack those intervention-related impacts that can help explain the reasons underpinning this apparent intervention success.

\subsection{Cognitive, task and relational impacts}

Figure 6 illustrates the structuring and ordering of the intervention-related impact data from specific first-order categories to more general, and researcher induced, second-order categories. Table 3 presents representative quotations and events that substantiate the secondorder themes we identified. Below we organise our findings around the second-order categories identified: cognitive-level impacts, task-level impacts, and relational-level impacts.

\section{PLACE FIGURE 6 ABOUT HERE}

\section{PLACE TABLE 3 ABOUT HERE}

\subsubsection{Cognitive-level impacts}

The data suggests that the intervention achieved a range of cognitive-level impacts on APT members related to the assemblage and integration of multiple and different views, knowledge, and expertise about projects. Both managers and social workers reported four cognitive impacts -namely, discovering, connection forming, detaching and valuing- that were facilitated by specific intervention workshops. For example, APT members stated that at the mapping and SSM workshops they were able to discover, with sheer surprise, aspects of their peers' work, expertise, and perspectives previously unknown to them.

"The [mapping] work with the ovals, and the [SSM] one about the projects, I thought were really cool because, for example, that [SSM] one I had to do it with Social Worker SW4 and I found out that she knew things about productive processes and the field of agroindustry that I didn't have a clue; [her knowledge about] the transformation of food for example, I was impressed. I found that [SSM work] to 
Please cite this article as:

Henao, F., \& Franco, L. A. Unpacking multimethodology: Impacts of a community development intervention. European Journal of Operational Research (2016) http://dx.doi.org/10.1016/j.ejor.2016.02.044

be really good as we could use a language that I thought I could not use with certain people." (Manager MG4)

"[SSM] was the best activity out of all of them because it allowed me to have a better understanding of how I felt about a project. It was a project about providing services of recycling waste, which we evaluated using this methodology. It allowed me to understand that despite the fact that my colleague and I had been working on the same project for 2 months, each one of us had different ideas about what the project was going to be. I always assumed that my colleague understood what I was communicating to him, and he felt the same way vice versa. But when we had to do the [rich picture] drawings, they were totally different, there was nothing in common. The only thing in common was the heading, despite the fact that we did the research together. Those perspectives of the same project, with the same title and the same objective, to be so different...I loved that because it allowed me to understand that we were both heading towards the same project but from different sides." (Social Worker SW5)

In addition, also at the mapping and SSM workshops, APT members were able to form connections across different domains of knowledge and expertise that helped them to build a more holistic and interdisciplinary view of their potential projects.

"And after all the ideas were put together and you showed us that map...that tree with all the ideas, it was good to see the links between some things and other things, and see also some of the ideas that we had, which at first did not seem to match at all or not point towards the same direction. Also seeing that there were factors present from both, the process as well as the social part [was good]...." (Manager MG4).

"Those spaces for discussion are very important because they allow us to analyze things from all points of views. There we could sort of have a look at what interdisciplinary is really about. Within the same disciplines we could look at a same issue and each one of us could contribute from our own knowledge, from our own capacities and our own potential... that is to enrich a process. That is interdisciplinary." (Social Worker SW3)

Forming connections was not only associated with the mapping and SSM workshops. The decision conferencing workshop also afforded APT members the opportunity to form connections across their disciplinary knowledge and expertise domains.

"I thought [the use of decision conferencing] was really cool because everybody participated in the development of the model, and it was developed by people who have different professional backgrounds. If it had been developed only by us, the managers, or only by the social workers, we would have ended up with very different developments from each group. It was actually developed with different people who had various opinions, different knowledge and each one made a contribution. Therefore, between all of us, we were saying; this gets more score, this gets less or this has already been defined, or this still has not been defined, or this which is not included needs defining.... So amongst plurality, the different branches, one specific point could be identified. I think it was really good at the end.” (Manager MG1)

"We were just looking at it from an economic perspective: no other aspect was being taken into account. It is what I was saying just now: we hadn't managed to put it all together. As a result, the project coordination saw the need to look at the projects as a whole, even if their main focus was economics.” (Social Worker SW3) 
Please cite this article as:

Henao, F., \& Franco, L. A. Unpacking multimethodology: Impacts of a community development intervention.

European Journal of Operational Research (2016) http://dx.doi.org/10.1016/j.ejor.2016.02.044

The evidence suggests that the discovering and connection forming impacts were equally experienced by both managers and social workers. By contrast, the detaching and valuing impacts were reported mostly by the social workers and the managers, respectively. Furthermore, detaching and valuing were generally associated with the decision conferencing workshops. In the case of social workers, decision conferencing afforded them the possibility to detach themselves from subjective project evaluations that were difficult to avoid due to the nature of their professional role. Specifically, decision conferencing enabled them to take on a more objective but still fair stance towards project evaluation.

"The thing with us social workers is that we become too passionate sometimes, all heart, all about
feelings but not objective. Therefore [the MM intervention] allowed me to see things from a different
and more objective point of view." (Social Worker SW6)

"I think that the [MM] intervention has been very useful because it allowed us to do a much more objective job, a lot more impartial. Defining the vulnerabilities in terms quasi-quantifiable and measurable so as not to just by hand picking figures, very subjectively. So as not to say 'it seems to me this family is like this...', but to be able to qualify it and quantify it, makes it a lot more precise, more objective, clearer and being able to know what things you are placing more value or less value on. If one says: is a family with kids more vulnerable, is a family that lives in more difficult conditions more vulnerable, one that has a lower income or a very poor level of education. This enables you to start qualifying, but without knowing which [particular] family you are talking about. Giving a value to the components or to the family elements, in a way which enables one to qualify, weigh, and say: 'this gave me this result' and that's it, regardless of who it might be." (Social Worker SW2)

On the other hand, the majority of managers attributed the ability to value different projects, thoroughly and quantitatively, to the use of decision conferencing. Indeed, interventionsupported valuation involved both comparing and contrasting projects in ways that the APT had not been used to do ever before.

\begin{abstract}
"I am a manager and I am obviously going to focus on numbers, but I look at it in HiView and it turns out that the economics part is not so important, but instead it is the ecological and the social part. So, I go and face up to those projects and I go to see the actual reality. It can be very good on the economic side but it does not provide me what I really need, which is in the social or the ecological parts, for example. Therefore this takes off my blindfold and says to me: My friend, wake up! You are approaching your project in the wrong manner!" (Manager MG1)
\end{abstract}

"The only way for one of these projects to be successful or not is because of the results to be obtained from them, and HiView showed us that this project should have a quantitative result. This could make us understand what definitely.... where we are achieving, what objectives we are realizing, if we are carrying out the projects or not, if the projects are viable or not.” (Manager MG6)

To summarise different intervention workshops (mapping, SSM, decision conferencing) achieved a range of cognitive-level impacts (discovering, connection forming, detaching, valuing) that enabled them to assemble and integrate multiple project-related perspectives, knowledge and expertise within the APT.

\title{
5.2.2. Task-level impacts
}

Task-level impacts concerning how APT members elaborated and refined their collective understandings of projects were also evident in the interview data. Two task-level impacts were identified: funnelling project planning efforts, and building a case for projects. Funnelling was related to how the intervention process was perceived to increase APT members' ability to direct project planning tasks down a structured path. 
Please cite this article as:

Henao, F., \& Franco, L. A. Unpacking multimethodology: Impacts of a community development intervention.

European Journal of Operational Research (2016) http://dx.doi.org/10.1016/j.ejor.2016.02.044

"I think this opportunity for planning things more worked out really well ... I mean the ability to turn all those business ideas into a process and that we could have a more holistic vision of it. I value very much the elements we considered for this analysis. So the contribution that came out from here was being able to have a vision of process, to analyze this first and then that next. So everything that followed from that was: first the problem diagnosis, then the design of specific business ideas, then the presentation of those business proposals and finally their evaluation. All that came out from the possibility of organizing everything, and it was something that I felt was missing and now I feel we have advanced a lot...”. (Manager MG3)

“...it was like learning to walk: like the process of learning to walk, to learn how to walk you first have to take one step, then two [steps], and then you come out and get running ... but, if you never take that first step how do you expect to walk? It was also an interlinked planning process. For example, to do the work that we did in pairs, I don't remember what it was called [SSM], we had to ground all these ideas first for the benefit of the team [using mapping]. This way the whole team could see where their ideas were, where their role within the whole process was, and how each project had to have an impact on different aspects.... And the same was with the HiView evaluation process, which was the one that gave us the power to make decisions" (Manager MG4)

Case building, on the other hand, was related to the work conducted by APT members between workshops, which involved making a business case for a project through information gathering activities (e.g. costing, scoring) that demanded significant interactions between APT members.

"The dynamics triggered by the intervention was the key. In my case with all the analysis we performed ... with the set of activities that we undertook in the collective mapping and the multicriteria [work]. Thanks to all of these together I was able to visualize the project in a more comprehensive way, which was fundamental for working with the other person. In other words, [the intervention] generated some concerns in all of us for which we did not have an answer, but which we had to look for. This generated a dynamic that required contributions from both of us, and for the project to be carried out we had to interact and get the information to be able to develop the project." (Manager MG6)

"I defended the attributes of the project that I thought seemed the most reasonable. All of us did the same. So, during the discussions we gave our opinion about criteria weights, even after having defined them we revisit them again. So it was a collective construction that came as a result of everyone's suggestions and presentations." (Manager MG5)

The perceived impact of the intervention on the ability to funnel project planning activity and build a case for a project was mostly reported by the managers. This finding should not be too surprising: project planning fell naturally within the APT managers' role and thus any mechanism that could assist them to perform that role more effectively was bound to be highlighted and appreciated. Overall, the planned sequence of intervention workshops and associated workshop preparation work afforded the APT with opportunities to undertake a closer and more structured examination of particular projects following a structured path.

\subsubsection{Relational-level impacts}


Please cite this article as:

Henao, F., \& Franco, L. A. Unpacking multimethodology: Impacts of a community development intervention.

European Journal of Operational Research (2016) http://dx.doi.org/10.1016/j.ejor.2016.02.044

In addition to the achievement of cognitive- and task-level impacts, the data suggests that, the intervention (as a whole or parts thereof) enabled the APT to develop team interactions they had not previously experienced. Two relational-level impacts were identified: minding and bonding, which were mostly highlighted by social workers and managers, respectively. Thus there is evidence that social workers became mindful of each other's perspectives about projects and the project planning process, and that these impacts were connected to all the mapping, SSM and decision conferencing workshops.

"We tend not to speak or understand the language employed by others, and due to our different professional backgrounds we tend to very narrow-minded in defending certain beliefs or positions, and don't bother to explain them to others. For example, there were times when we said things like: 'from the point of view of human capital we do not agree about $X$ because it may harm the family's social fabric or because it may weaken the family', but we never explained why the family could be weakened. We assumed that the managers, who have no social work training or knowledge, would understand us. The same thing happened with the managers. For example, when they told us that a project was a good prospect, with profitability about $70 \%$, and we argued back that money was not all that matters. But they never explained to us the meaning of that figure, or how they calculated it, so we would understand its meaning better. So, the [MCDA] exercise allowed us to sit down, both social workers and managers together, to discuss in detail each project. As a result, we even sometimes ended up helping the managers with the calculator, while the managers ended up supporting us during workshops with the community so that they could understand the dynamics of those groups. So, all this in turn strengthens the team. "(Social Worker SW5)

"We learned to respect and appreciate each other's opinion and as a result we all grew. For example, I said [during workshops]: 'for this project, from the social side, this is required', then the managers intervened and replayed 'very important, but from the economic side this is what is needed' ... so this type of discussions enriched us a lot. "(Social Worker SW3)

The evidence suggests that the intervention enabled managers to bond with their social working peers by reaching out to them, and communicating more with them. Similarly to the case of the minding impact, the bonding impact was attributed to all the intervention workshops.

"So, I think one of the important aspects of this process was that it encouraged us to look for help, like saying; here I am, come and help me! You already know more about this, explain it to me, teach me!, and the need to learn from everyone. This I think was a very good process and I think this is what stands out the most for me: the fact that everyone says how you analyzed that, this project, how would you consider this. So this is when the debate and the evaluation started with all the criteria we had." (Manager MG4).

"On the [SSM] activity we did in pairs to develop the ideas. As I said, it allowed for the people who are part of this team to interact and to get to know each other better, also we worked on very specific things. And it was something at random, I mean it was not done with the colleagues I usually work with or the ones I want to work with, but the pairs were formed at random. I had to work with people I had not worked with before. This contributed a lot in terms of letting me know them better and strengthen the relationship I have with these colleagues. "(Manager MG1)

As the above interview quotes illustrate, relational-level impacts (minding, bonding) assisted APT in developing team interactions that had not been experienced before. 
Some of the impacts identified from our analysis are consistent with claims normally made about OR interventions in general, and multimethodology interventions in particular. For example, successful interventions can enable participants to discover and learn new things of their own situation by appreciating other people's point of view (e.g. Franco \& Lord, 2011; Howick \& Ackermann, 2011; Rouwette, Vennix, \& Van Mullekom, 2002) and being mindful about their difficulties and struggles (e.g. Marttunen \& Suomalainen, 2005; Petkov, Petkova, Andrew, \& Nepal, 2007; White \& Lee, 2007). Successful interventions can also help those involved to appreciate the systemic nature of issues, decisions or behaviours by forming connections between them (e.g. Ackermann, Eden, \& Williams, 1997; Eden, Williams, Ackermann, \& Howick, 2000; Franco \& Lord, 2011; Williams et al., 2003). Additionally, the literature recognises the transparency of the models and the intervention process itself as one of the most common positive impacts of OR interventions (e.g.Franco, 2009; Hjortsø, 2004; Howick \& Ackermann, 2011; Namen, Bornstein, \& Rosenhead, 2009; White \& Taket, 1994). We relate transparency in the context of our own intervention as the possibility that team members had to perform objective valuations of their business ideas and being able to detach themselves from who would be the beneficiaries of those projects. Finally, some OR scholars have reported benefits that may influence team bonding, such as managing group conflicts, enhancing team building, and changing participants' attitude regarding the way they approach the problem at hand, or the way they work with their peers (e.g Bryant \& Chin, 2000; Franco \& Lord, 2011; White \& Tacket, 1997).

In summary, the preceding analysis suggest a number of realised impacts attributed to the intervention that are commonly reported in the literature, and are associated with reported changes in the personal, social and material worlds of those involved. These realised impacts were evident at cognitive (discovering, connection forming, detaching, valuing), task (funnelling, case building), and relational (minding, bonding) levels, and were deemed as positive by all APT members. It is worth stressing, however, that our intervention was not always perceived as positive by the participants. Indeed, some difficulties were encountered along the way, particularly in the early stages of the intervention. For instance, some participants considered that the intervention process was time-consuming, primarily for finding accurate and reliable data to feed the evaluation model. Others showed concern about the time elapsed between workshops, which caused the intervention to lose momentum. Few participants felt that some of the activities were a little overwhelming, particularly those that required them to make numerical evaluations. As a result, they felt anxious when they had to report their calculations at a meeting with the facilitator and the rest of the group. Finally, some participants recognised to have experienced some frustration when the valuation of their business ideas did not come out as they had originally expected.

\section{Discussion}

In this section we build from the preceding examination of our data to propose a tentative but empirically grounded process model that suggests how variations in an intervention's analytic and relational capabilities affects decision making efforts and integrative behaviours that have implications for change. We also discuss how the research presented here contributes to the work on multimethodology evaluation. Finally, we provide insights for multimethodology practitioners to show how models can be designed to exhibit requisite analytic and relational capability so that the likelihood of change is increased.

\subsection{A process model of multimethodology intervention impact}


Franco (2013) shows how effective model-supported interventions must exhibit sufficient analytic and relational capabilities in order to lead to change. Analytic capability is associated with the capacity of an intervention to effectively represent participants' differences and dependencies concerning a problem or task of mutual concern. Relational capability, on the other hand, is associated with the capacity of an intervention to enable interactional spaces conducive to integrative behaviours among those involved. Representing differences and facilitating integrative behaviours are typically achieved through model-supported processes such as the mapping, SSM and decision conferencing workshops deployed in the intervention examined here. Furthermore, the notions of an intervention's analytic and relational capabilities can be linked to the intervention impacts discussed above. Empirically-driven insights from our research suggest that the intervention examined here had the (analytic) capacity to increase decision making efforts and the (relational) capacity to foster integrative behaviours, as evidenced by the bundle of cognitive, task and relational impacts reported and attributed to the intervention.

Our findings resonate with recent work in social psychology maintaining that the use of appropriate incentive mechanisms increases the decision making efforts and integrative behaviours of individuals and groups, which are the critical factors responsible for effectiveness of decision making and change (De Dreu, Beersma, Stroebe, \& Euwema, 2006). Deliberate decision making effort is associated with the notion of 'epistemic motivation' (Kruglanski, Dechesne, Orehek, \& Pierro, 2009), and conscious integrative behaviour is related to the concept of 'social motivation' (De Dreu, Weingart, \& Kwon, 2000). "Epistemic motivation refers to the willingness to expend effort to achieve a thorough, rich, and accurate understanding of the world, including the group task or decision problem at hand. Social motivation is defined as the individual preference for outcome distributions between oneself and other group members and can be proself (i.e. the individual is concerned with own outcomes only) and prosocial (i.e. the individual is concerned with joint outcomes and fairness.” (De Dreu, Nijstad, \& Van Knippenberg, 2008, p. 23, our emphasis). A decision process that supports the careful and transparent elicitation and structuring of different perspectives is more likely to facilitate the engagement and contributions of those involved, and thus increase their epistemic motivation because such a process would be seen as conducive to decision outcomes that are 'procedurally rational' (Eden \& Ackermann, 2010; Simon, 1976). Furthermore, a decision process that allows those involved to 'have their say' and be listened to is likely to increase pro-social motivation, as the process would be seen as being ‘procedurally just’ (Eden \& Ackermann, 2010; Kim \& Mauborgne, 1995).

In line with these ideas, evidence from our data suggests that the use of different model-based processes in a multimethodology intervention incentivised the epistemic motivation of APT members to engage in effortful decision making, as these processes supported more deliberate engagement in cognitive and task-related activities (discovering, forming connecting, funnelling, etc.) that would have been usually carried out heuristically or as taken-for-granted routines. Similarly, evidence from our data suggests that the intervention processes incentivised the social motivation of APT members to relate to one another in a non-calculative manner, as these processes provided spaces conducive to integrative behaviours (minding, bonding) that are indicative of 'relational engagement' (Tsoukas, 2009) between those involved.

Figure 7 presents a tentative process model that summarises our findings. The model should be taken as an empirically-grounded hypothesis stating that, for any intervention, increases in 
its analytic and relational capabilities are likely to incentivise the decision making efforts and integrative behaviours of those involved in the intervention. The levels of decision making effort and integrative behaviours observed will in turn realise a bundle of cognitive, task and relational impacts, whose size will affect the degree of change that is achieved in the personal, social and material worlds of those involved. Finally, the model underlines the potential feedback effects of sizeable changes in personal, social and material worlds, which are likely to reinforce decision-making efforts and integrative behaviours in the long run.

\section{PLACE FIGURE 7ABOUT HERE}

\subsection{Implications for multimethodology research and practice}

The work presented here has a number of implications for multimethodology research and practice. In terms of research, our study shows how Mingers \& Brocklesby's (1997) theoretical framework can be used not only to design a multimethodology intervention, but also as a useful organising device to reflect upon intervention outputs. By using this framework in this way, we go beyond simply sharing experiences and lessons in a storytelling or anecdotal manner, and move towards a more structured and systematic way of reflecting upon intervention evaluation data. This approach to evaluation demands that operational researchers reveal their expectations in terms of impacts upfront while designing their intervention; collect evaluation intervention data before, during and after the intervention; and finally contrast those initial expectations with the impacts realised in practice.

More specifically, our study reports empirical evidence that agrees with the general assumption that multimethodology can create impacts across all three interventions domains: personal (cognitive: discovering, connection forming, detaching, valuing), social (relational: minding, bonding), and material (task: funnelling, case building). For example, cognitive mapping, SSM and decision conference encouraged participants, in different ways, to explore the elements of their own intervention with more care. This allowed them to discover aspects of their own intervention they did not know before, encouraged them to make further connections between the social and managerial elements of the problem context, questioned their initial rationale making them more mindful towards other people's perspectives, and strengthen their ability and willingness to build stronger business cases.

Our findings also support the theoretical assumption that individual methodologies within a multimethodology intervention complement each other. In the Moravia intervention for example, the mapping, SSM and decision conferencing workshops jointly contributed to cognitive impacts such as connection forming, yet only decision conferencing seemed to have triggered cognitive impacts such as detaching and valuing. In addition, the sequence of intervention activities, rather than the methodologies themselves, seemed to be responsible for task-related impacts such as funnelling and case building. This means that the whole intervention may have produced greater impacts than each methodology would have individually.

In terms of multimethodology practice, a key implication of our study is that operational researchers may consider upfront the analytic and relational capabilities required for the intervention context at hand, and choose their mix of methodologies (or parts thereof) 
accordingly. Thus, practitioners may take into consideration aspects such as how to incentivise participants' decision-making efforts or enhance further their integrative behaviours for the benefit of their designed intervention. For example, Soft OR tools such as rich pictures could be employed individually with each member of a decision team to discuss an issue of concern, and then contrast all the pictures created to uncover differences in perception among individuals. This may help them to discover elements of the situation they did not know before and encourage them to be more mindful about other people's perspectives. On the other hand, quantitative approaches such as multi-criteria evaluation or simulation could be used to direct a team's effort when evaluating social projects and strengthen their abilities to build stronger cases in favour or against a project or strategic initiative. This way of thinking about interventions may also be extended to non-OR techniques. For example role-playing techniques could be employed to enhance minding and the devil's advocacy technique could be used for case building. These design considerations should be carefully constructed but cannot be separated from the context of the intervention. Indeed the design of many OR interventions, particularly those with an emphasis on problem structuring support, can be subject to change due to cultural, social and political factors.

\section{Conclusion}

This paper presented a detailed account of a multimethodology intervention designed and deployed to support the planning of business ideas by a management team working in a development context. In line with recent calls for more empirical studies that increase our understanding of the realised impacts of multimethodology interventions (Howick and Ackermann 2011), the research reported here identifies a range of cognitive, task and relational-related impacts experienced by the management team. In addition, our analysis helped us to develop a process model that explains the mechanisms for the personal, social and material changes reported by those involved. The model explains how the intervention's analytic and relational capabilities triggered effortful decision-making processes and integrative behaviours, which underpinned the reported impacts and changes.

Whilst this research has provided some empirical evidence and associated implications for the research and practice of multimethodology, there are at least three limitations that must be acknowledged. First, there is always the question of whether some or all of the reported impacts in this study could have been due to the facilitator. Indeed, it is generally recognized that there is a facilitator effect in most facilitated interventions (Ackermann, 1996; Franco \& Montibeller, 2010; Phillips \& Phillips, 1993; Taket, 2002). Second, our research was based on a single case study and a particular multimethodology. What would have happened if an alternative combination of methods had been used is certainly worth asking. However, the uniqueness of a situation in which a particular multimethodology is applied makes this kind of inquiry infeasible in practice. A group like the APT, for example, is in many ways unique because it operates in a Latin American context and faces a problematique that is related to that context. Nevertheless, given the impacts reported from the application of our multimethodology, the possibility that the same multimethodology, or alternative multimethodologies, could have similar effects with other groups like the APT within and outside the Latin American context clearly deserves further investigation. This would help to validate our findings and test further the process model elaborated here. The third main limitation stems from our reliance on interviews as our main source of evaluation data. As Eden $(1995,2000)$ observes, the use of interview data can be problematic because interviewees recall of the intervention may be biased due to a number of reasons including memory limitations, imaginative reconstruction, oversimplification, and wishful thinking. 
One way to overcome this in future studies would be to triangulate interview data with other data sources such as video and structured questionnaires.

To conclude, we hope that our findings encourage operational researchers to consider the analytical as well as relational capabilities of their deigned interventions. For these are important dimensions responsible for the realised impacts of methodologies at cognitive, task and relational levels.

\section{Acknowledgment}

This research was possible thanks to the support of a Dorothy Hodgkin Postgraduate Award received in the United Kingdom during the years 2005 to 2009. The authors would also like to thank Antioquia Presente for granting us access and letting us be part of the Moravia project.

\section{References}

Ackermann, F. 1996. Participant's perceptions on the role of facilitators using group decision support systems. Group Decision and Negotiation, 5(1): 93-112.

Ackermann, F., \& Eden, C. 2010. Strategic Options Development and Analysis. In M. Reynolds, \& S. Holwell (Eds.), Systems Approaches to Managing Change: A Practical Guide: 135-190. London: Springer.

Ackermann, F., Eden, C., \& Williams, T. 1997. Modeling for litigation: Mixing qualitative and quantitative approaches Interfaces, 27(2): 48-65

Belton, V., Ackermann, F., \& Shepherd, I. 1997. Integrated Support from Problem Structuring through to Alternative Evaluation Using COPE and VISA. Journal of Multi-Criteria Decision Analysis, 6(3): 115-130.

Belton, V., \& Stewart, T. J. 2002. Multiple Criteria Decision Analysis: An integrated approach. Dordrecht: Kluwer.

Bennett, P. G. 1985. On Linking Approaches to Decision-Aiding: issues and prospects. Journal of Operational Research Society, 36(8): 659-669.

Brown, J., Cooper, C., \& Pidd, M. 2006. A Taxing Problem: the complementary use of hard and soft OR in the public sector. European Journal of Operational Research, 172(2): 666-679.

Bryant, J. W., \& Chin, C. K. 2000. Integrating approaches to revitalise a church's mission strategy. Journal of the Operational Research Society, 51(1): 689-699.

Bryson, J. M., Ackermann, F., Eden, C., \& Finn, C. 2004. Visible Thinking: unlocking causal mapping for practical business results. Chichester: Wiley.

Checkland, P., \& Poulter, J. 2006. Learning for Action: a short definitive account of Soft Systems Methodology and its use for practitioners, teachers and students. Chichester: Wiley.

Checkland, P., \& Scholes, J. 1990. Soft Systems Methodology in Action. Chichester: Wiley.

Cropper, S. 1990. Variety, formality, and style: Choosing amongst decision-support methods. In C. Eden, \& J. Radford (Eds.), Tackling Strategic Problems: the role of group decision support: 92-98. London: Sage.

Czarniawska, B. 2004. Narratives in social science research. London: Sage. 
De Dreu, C. K., Beersma, B., Stroebe, K., \& Euwema, M. C. 2006. Motivated information processing, strategic choice, and the quality of negotiated agreement. Journal of Personality and Social Psychology, 90(6): 927-943.

De Dreu, C. K., Weingart, L. R., \& Kwon, S. 2000. Influence of social motives on integrative negotiation: A meta-analytical review. Journal of personality and Social Psychology, 78(5): 889-905.

De Dreu, C. K. W., Nijstad, B. A., \& Van Knippenberg, D. 2008. Motivated information processing in group judgment and decision making. Personality and social psychology review, 12(1): 22-49.

Eden, C. 1995. On evaluating the performance of ‘wide-band' GDSS’s. European Journal of Operational Research, 81: 302-311.

Eden, C. 2000. On evaluating the performance of GSS: furthering the debate, by Paul Finlay (European Journal of Operational Research 107, pp 193-201) -a response by Colin Eden. European Journal of Operational Research, 81(120): 218-222.

Eden, C., \& Ackermann, F. 2010. Decision making in groups: theory and practice. In P. C. Nutt, \& D. C. Wilson (Eds.), Handbook of decision making: 231-272. Chichester, UK: Wiley-Blackwell.

Eden, C., Ackermann, F., Bryson, J. M., Richardson, G. P., \& Andersen, D. F. 2009. Integrating modes of policy analysis and strategic management practice: Requisite elements and dilemmas. Journal of the Operational Research Society, 60(1): 2-13.

Eden, C., Williams, T., Ackermann, F., \& Howick, S. 2000. The role of feedback dynamics in disruption and delay: On the nature of disruption and delay (D\&D) in major projects. Journal of the Operational Research Society, 51(3): 291-300.

Eisenhardt, K. 2002. Building theories from case study research. In A. M. Huberman, \& M. B. Miles (Eds.), The qualitative researcher's companion: Classical and contemporary readings: 5-35. Thousand Oaks, CA: Sage.

Ferreira, J. S. 2013. Multimethodology in Metaheuristics. Journal of the OPerational Research Society, 64(6): 873-883.

Flood, R. L., \& Jackson, M. 1991. Creative Problem Solving: Total Systems Intervention. Chichester: Wiley.

Franco, L. A. 2009. Problem Structuring Methods as Intervention Tools: reflections from their use with multi-organizational teams. OMEGA: The International Journal of Management Science, 37(1): 193-203.

Franco, L. A. 2013. Rethinking Soft OR interventions: Models as boundary objects. European Journal of Operational Research, 231(3): 720-733.

Franco, L. A., \& Lord, E. 2011. Understanding multi-methodology: evaluating the perceived impact of mixing methods for group budgetary decisions. Omega, 39: 362-372.

Franco, L. A., \& Montibeller, G. 2010. Facilitated modelling in operational research. European Journal of Operational Research, 205(3): 489-500.

Glaser, B., \& Strauss, A. 1967. The Discovering of Grounded Theory. Chicago: Aldine.

Gondal, S. 2004. Initernet and technology New Venture Development using Soft OR. European Journal of Operational Research, 152(3): 571-585.

Henao, F., Cherni, J. A., Jaramillo, P., \& Dyner, I. 2012. A multicriteria approach to sustainable energy supply for the rural poor. European Journal of Operational Research, 218(3): 801-809.

Hindle, G., \& Franco, L. A. 2009. Combining problem structuring methods to conduct applied research: a mixed methods approach to studying fitness-to-drive in the UK. Journal of the Operational Research Society, 60(12): 1637-1648. 
Hjortsø, C. N. 2004. Enhancing public participation in natural resource management using Soft OR - an application of strategic option development and analysis in tactical forest planning. European Journal of Operational Research, 152(3): 667-683.

Howick, S., \& Ackermann, F. 2011. Mixing OR methods in practice: Past, present and future directions. European Journal of Operational Research, 215(3): 503-511.

Jackson, M. 2009. Managing the tensions created by mixing methods: Comments for Eden et al from a critical systems perspective. Journal of the Operational Research Society, 60: 1297-1299.

Jackson, M., \& Keys, P. 1984. Towards a System of Systems Methodologies. Journal of the Operational Research Society,, 35(6): 473-486.

Keys, P. 2006. On becoming expert in the use of problem structuring methods. Journal of the Operational Research Society, 57: 822-829.

Kim, W. C., \& Mauborgne, R. A. 1995. A procedural justice model of strategic decision making. Organization Science, 6: 44-61.

Kotiadis, K., \& Mingers, J. 2006. Combining PSMs with hard OR methods: the philosophical and practical challenges. Journal of the Operational Research Society, 57(7): 856867.

Kruglanski, A., Dechesne, M., Orehek, E., \& Pierro, A. 2009. Three decades of lay epistemics: The why, how, and who of knowledge formation. European Review of Social Psychology, 201(1): 146-191.

Lincoln, Y. S., \& Guba, E. G. 1985. Naturalistic Inquiry. Beverly Hills, CA: Sage.

Locke, K. 2001. Grounded theory in management research. London: Sage.

Marttunen, M., \& Suomalainen, M. 2005. Participatory and multiobjective development of watercourse regulation: Creation of regulation alternatives from stakeholders' preferences. Journal or Multi-Criteria Decision Analysis, 13(1): 29-49.

Midgley, G. 1997. Mixing methods: Developing systemic intervention. In J. Mingers, \& A. Gill (Eds.), Multimethodology: The theory and practice of combining Management Science methodologies: 249-290. Chichester: Wiley.

Mingers, J. 1997. Multi-paradigm mutlimethodology. In J. Mingers, \& A. Gill (Eds.), Multimethodology: The Theory and Practice of Combining Management Science Methodologies, Vol. 1-20. Chicester: Wiley.

Mingers, J. 2000. Variety is the Spice of Life: combining soft and hard OR/MS methods. International Transactions in Operational Research, 7(6): 673-691.

Mingers, J. 2001. Multimethodology: mixing and matching methods. In J. Rosenhead, \& J. Mingers (Eds.), Rational Analysis for a Complex World Revisited: problem structuring methods for complexity, uncertainty and conflict: 289-310. Chichester: Wiley.

Mingers, J. 2003. A Classification of the Philosophical Assumptions of Management Science Methods. Journal of the Operational Research Society, 54(6): 559-570.

Mingers, J., \& Brocklesby, J. 1997. Multimethodology: towards a framework for mixing methodologies. OMEGA, 25(5): 489-509.

Mingers, J., \& Rosenhead, J. 2004. Problem Structuring Methods in Action. European Journal of Operational Research, 152(3): 530-554.

Montibeller, G., Franco, L. A., Lord, E., \& Iglesias, A. 2009. Structuring Resource Allocation Decisions: a framework for building multi-criteria portfolio models with area-grouped projects. European Journal of Operational Research, 199(3): 846-856.

Namen, A. A., Bornstein, C. T., \& Rosenhead, J. 2009. Robustness analysis for sustainable community development. Journal of the Operational Research Society, 60(5): 587597. 
O'Reilly, K. 2005. Ethnographic methods. London: Routledge.

Ormerod, R. J. 1998. Putting Soft OR methods to work: Information systems strategy development at Parabola. OMEGA, 26(1): 75-98.

Ormerod, R. J. 2001. Mixing methods in practice. In J. Rosenhead, \& J. Mingers (Eds.), Rational analysis for a problematic world revisited: Problem structuring methods for complexity, uncertainty and conflict: 311-336. Chichester: Wiley.

Ormerod, R. J. 2008. The transformation competence perspective. Journal of the Operational Research Society, 59(11): 1435-1448.

Ormerod, R. J. 2014. OR competences: the demands of problem structuring methods. EURO Journal on Decision Processes, 2(3-4): 313-340.

Orton, J. D. 1997. From inductive to iterative grounded theory: Zipping the gap between process theory and process data. Scandinavian Journal of Management, 13: 419-438.

Petkov, D., Petkova, O., Andrew, T., \& Nepal, T. 2007. Mixing Multiple Criteria Decision Making with soft systems thinking techniques for decision support in complex situations. Decision Support Systems, 43(4): 1615-1629.

Phillips, L. 2007. Decision Conferencing. In W. Edwards, R. Miles Jr, \& D. von Winterfeldt (Eds.), Advances in Decision Analysis: from foundations to applications: 375-399. New York: Cambridge University Press.

Phillips, L. D., \& Phillips, M. C. 1993. Facilitated work groups: theory and practice. Journal of the Operational Research Society, 44(6): 533-549.

Pidd, M. 2004. Complementarity in systems modelling. In M. Pidd (Ed.), Systems Modelling: theory and practice: 1 -20. Chichester: Wiley.

Pollack, J. 2009. Multimethodology in series and parallel: strategic planning using hard and soft OR. Journal of the Operational Research Society, 60(2): 156-167.

Rosenhead, J., \& Mingers, J. (Eds.). 2001. Rational Analysis for a Problematic World Revisited: problem structuring methods for complexity, uncertainty and conflict. Chichester: Wiley.

Rouwette, E. A. J. A., Vennix, J. A. M., \& Van Mullekom, T. 2002. Group model building effectiveness. A review of assessment studies. System Dynamics Review, 18(1): 5-45.

Shah, S., \& Corley, K. 2006. Building better theory by bridging the quantitative-qualitative divide. Journal of Management Studies, 43(8): 1821-1835.

Simon, H. A. 1976. From Substantive to Procedural Rationality. In S. J. Latsis (Ed.), Method and appraisal in Economics. Cambridge: Cambridge University Press.

Small, A., \& Wainwright, D. 2014. SSM and technology management: Developing multimethodology through practice. European Journal of Operational Research, 233(3): 660-673.

Sørensen, L., Vidal, R. V. V., \& Engstrom, E. 2004. Using soft OR in a small company: The case of Kirby. European Journal of Operational Research, 152(3): 555-570.

Strauss, A., \& Corbin, J. 1998. Basics of Qualitative Research: techniques and procedures for developing grounded theory. London: Sage.

Suddaby, R. 2006. From the editors: What grounded theory is not Academy of Management Journal, 49(4): 633-642.

Taket, A. 2002. Facilitation: some contributions to theorising the practice of operational research. Journal of the Operational Research Society, 53(2): 126-136.

Tako, A. A., \& Kotiadis, K. 2015. PartiSim: A multi-methodology framework to support facilitated simulation modelling in healthcare. European Journal of Operational Research, 244(2): 555-564.

Tsoukas, H. 2009. A Dialogical Approach to the Creation of New Knowledge in Organizations. Organization Science, 20(6): 941-957. 
van Maanen, J. 2002. The fact of fiction in organizational ethnography. In A. M. Huberman, \& M. B. Miles (Eds.), The qualitative researcher's companion: Classic and contemporary readings: 101-117. Thousand Oaks, CA: Sage.

White, L. 2009. Understanding Problem Structuring Methods Interventions. European Journal of Operational Research, 99(3): 823-833.

White, L., \& Lee, G. J. 2007. Operational Research and sustainable development: Tackling the social dimension. European Journal of Operational Research, 193(3): 683-692.

White, L., \& Tacket, A. 1997. Critiquing multimethodology as metamethodology: Working towards pragmatic pluralism. In J. Mingers, \& A. Gill (Eds.), Multimethodology: The theory and practice of combining Management Science methodologies.: 379-405. Chichester: Wiley.

White, L., \& Taket, A. 1994. The death of the expert. Journal of the Operational Research Society, 45(7): 733-748.

Williams, T. M., Ackermann, F., \& Eden, C. 2003. Structuring a delay and disruption claim: An application of cause-mapping and system dynamics. European Journal of Operational Research, 148(1): 192.

Wilson, B. 2001. Soft Systems Methodology: Conceptual model building and its contribution. Chichester: Wiley.

Yearworth, M., \& White, L. 2013. The uses of qualitative data in multimethodology: Developing causal loop diagrams during the coding process. European Journal of Operational Research, 231(1): 151-161.

Zhu, Z. 2011. After paradim: why mixing-methodology theorising fails and how to make it work again. Journal of the Operational Research Society, 62(4): 784-798. 
Please cite this article as:

Henao, F., \& Franco, L. A. Unpacking multimethodology: Impacts of a community development intervention. European Journal of Operational Research (2016) http://dx.doi.org/10.1016/j.ejor.2016.02.044

Table 1: Characteristics of the intervention context.

Dimension

Description

Need to develop, assess and implement effective business ideas, with a view to enhance

Material the lives of members of the Moravian community (but without direct community input for the task).

Partial experience of planning tasks; contrasting views between managers and social workers

Personal about how to undertake the task; little understanding of roles within APT; perceived lack of consistency and objectivity in APT decision-making practices.

Tensions between some social workers and

Social APT leader; issues of voice and communication within APT. 
Please cite this article as:

Henao, F., \& Franco, L. A. Unpacking multimethodology: Impacts of a community development intervention. European Journal of Operational Research (2016)

Table 2: Intervention design and expected intervention impacts

\begin{tabular}{|c|c|c|c|c|c|c|}
\hline & & \multicolumn{4}{|c|}{ Intervention activity } & \multirow{2}{*}{$\begin{array}{l}\text { Expected } \\
\text { impacts }\end{array}$} \\
\hline $\begin{array}{l}\text { Problem } \\
\text { dimension }\end{array}$ & Method & Appreciation & Analysis & Assessment & Action to bring about changes & \\
\hline \multirow{3}{*}{ Material } & $\begin{array}{l}\text { Decision } \\
\text { conferencing }\end{array}$ & & & $\begin{array}{l}\text { A selected set of alternative business } \\
\text { ideas are assessed using MCDA }\end{array}$ & $\begin{array}{l}\text { An action plan is developed for } \\
\text { the chosen business ideas. }\end{array}$ & \multirow{3}{*}{$\begin{array}{l}\text { Implementation } \\
\text { of potentially } \\
\text { effective } \\
\text { business ideas } \\
\text { by APT. }\end{array}$} \\
\hline & $\begin{array}{l}\text { Soft systems } \\
\text { methodology }\end{array}$ & & & $\begin{array}{l}\text { Further details about business ideas } \\
\text { are analysed using CATWOE and } \\
\text { human activity systems modelling. }\end{array}$ & No specific action. & \\
\hline & Field visits & $\begin{array}{l}\text { Issues affecting physical circumstances of } \\
\text { Moravian community are appreciated by } \\
\text { analysts. }\end{array}$ & & & No specific action & \\
\hline \multirow{3}{*}{ Personal } & $\begin{array}{l}\text { Cognitive } \\
\text { mapping }\end{array}$ & $\begin{array}{l}\text { APT members' perspectives are } \\
\text { appreciated by analysts through cognitive } \\
\text { maps, which are then merged into a single } \\
\text { map. }\end{array}$ & $\begin{array}{l}\text { Causal structure of the different } \\
\text { perspectives contained in cognitive } \\
\text { maps are analysed using Decision } \\
\text { Explorer. }\end{array}$ & & No specific action & \multirow{3}{*}{$\begin{array}{l}\text { Changes in the } \\
\text { thinking and } \\
\text { knowledge of } \\
\text { APT members. }\end{array}$} \\
\hline & $\begin{array}{l}\text { Group causal } \\
\text { mapping }\end{array}$ & $\begin{array}{l}\text { APT members appreciate each other's } \\
\text { perspectives through merged map } \\
\text { (derived from cognitive maps) during } \\
\text { workshop, which is then updated on-the- } \\
\text { spot as further appreciation takes place. }\end{array}$ & $\begin{array}{l}\text { Causal structure of the different } \\
\text { perspectives contained in group map } \\
\text { are analysed using Decision Explorer. }\end{array}$ & $\begin{array}{l}\text { Areas within which business ideas } \\
\text { can be developed are qualitatively } \\
\text { assessed and prioritised. }\end{array}$ & $\begin{array}{l}\text { Final merged map and candidate } \\
\text { priority areas are used to generate } \\
\text { agreements about the subsequent } \\
\text { development of business ideas. }\end{array}$ & \\
\hline & $\begin{array}{l}\text { Decision } \\
\text { conferencing }\end{array}$ & & & & $\begin{array}{l}\text { Set of business ideas resulting } \\
\text { from the analysis is used as a } \\
\text { basis to generate agreements } \\
\text { about what business ideas to } \\
\text { select and implement. }\end{array}$ & \\
\hline Social & $\begin{array}{l}\text { Cognitive } \\
\text { mapping }\end{array}$ & $\begin{array}{l}\text { Working practices and social relations } \\
\text { amongst APT members are (indirectly) } \\
\text { appreciated by analysts through cognitive } \\
\text { mapping interviews. }\end{array}$ & & & No specific action & $\begin{array}{l}\text { Improved } \\
\text { working } \\
\text { practices and } \\
\text { social relations } \\
\text { amongst APT }\end{array}$ \\
\hline
\end{tabular}




\begin{tabular}{|c|c|c|c|c|}
\hline & $\begin{array}{l}\text { Group causal } \\
\text { mapping }\end{array}$ & $\begin{array}{l}\text { Working practices and social relations } \\
\text { amongst APT members are } \\
\text { (indirectly) analysed by analysts } \\
\text { through group causal mapping } \\
\text { workshop. }\end{array}$ & No specific action & members. \\
\hline
\end{tabular}

Table 3: Data categories and illustrative excerpts

\section{Second- and first-}

\section{Illustrative excerpts}

order categories

1. Cognitive impacts

A. Discovering

[About cognitive mapping] It was really good because there was a brainstorm of ideas and there we could learn about some of the perceptions people had about the project. Perceptions they were not able to express or say openly." (Social Worker SW4)

B. Connection

forming

"You showed us a very good perspective of the whole process. We could see the project and the intervention that we wanted to carry out from a general view, without limiting ourselves to specific points or staying focused only on the critical points of each process.” (Manager MG4)

C. Detaching

"And it [the planning process] was very good. And I think it is more transparent at the moment of helping out or making a donation....it allows you not to be influenced by the name of the person (beneficiary), because sometimes people strike a chord with you and you say; lets help Mr So and So, poor thing, he comes to see us a lot, he is very committed and because of this we end up forgetting about $\mathrm{Mr} X$, who is the one who really needed help. This exercise allowed that: It allowed help to be offered without any influence from the emotional side of things." ( Social Worker SW4)

D. Valuation

2. Task-level impacts

E. Funnelling

F. Case building
"I was pleasantly surprised because I could clearly see what the strength of my project was: My project is strong on the social part or my project is strong on the economic part. I liked it very much because I managed to identify, I managed to give information about my own project, and I also managed to give information that I might have had qualified. I know my project is good in the economic part, but the good thing is that I know it in numbers; how much in percentages, in numbers how much it is, what it represents." (Manager MG1)

"Benefits?, I would say that first a very conscious analysis of the different types of projects. Also, the economic evaluation, to ground the project to a reality based on basic tools. Tools such as the financial information, the information of the team itself, the perception of the team towards the project, the permanent communication between the different areas in this case the different lines, evaluating the projects and the possibilities of continuing or not, the time, the scope. All evaluations are welcome but specially this one which was very much in line and very beneficial for that specific moment we were going through. At that moment we did not have a clear understanding of the projects we were going to work on. This helped to redirect the analysis of the projects and where we had to direct ourselves as economic operators." (ManagerMG6)

Did the workshops we had help to structure the businesses ideas or conceptualize them? ..... It forced us to research a little bit more. To look for other sources of financing: Not to stay only with what the corporation has. To select the beneficiaries better, because the profile of those people who are going to be part of the project is important. We thought with 10 families we can start, we choose whoever we want to choose...but things weren't like that. The selection of the beneficiaries should be a little more detailed in every sense. It is almost as if staff was going to be chosen for a normal company." (Manager MG2) 
Please cite this article as:

Henao, F., \& Franco, L. A. Unpacking multimethodology: Impacts of a community development intervention. European Journal of Operational Research (2016)

http://dx.doi.org/10.1016/j.ejor.2016.02.044

3. Relational impacts

G. Minding

"With the exercise and with the HiView we could become aware of the complex issues of the project, what was being done, why the other workmates has presented it that way, and we put ourselves in their place: If I was on that same line, how would I have set it up? (Social Worker SW5)

H. Bonding

[a benefit about MCDA was for example] "if I ask a workmate for help, he will offer it. We are workmates and if he/she helps me to do things and that I value. The same way if someone asked me something, I would ask, how are you getting on with that and if they told me that they still hadn't done something, I would try to help them with that particular part. Therefore a task (performed in a software) which was individual, where each person had to input its own the information, became a task on which one could receive support from other workmates. And if they supported you, you were left with a feeling of gratitude that you are going to be able to complete it”. (Manager MG1) 
Please cite this article as:

Henao, F., \& Franco, L. A. Unpacking multimethodology: Impacts of a community development intervention. European Journal of Operational Research (2016) http://dx.doi.org/10.1016/j.ejor.2016.02.044

Figure 1: The district of Moravia in Medellin, Colombia (picture taken in January 2007).

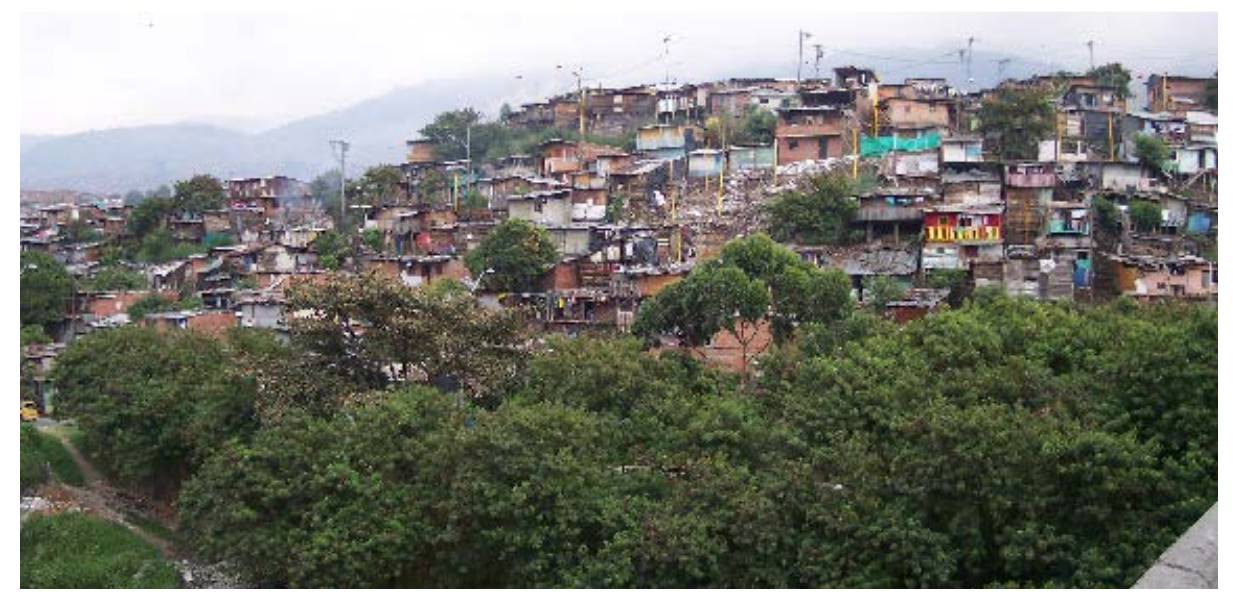


Please cite this article as:

Henao, F., \& Franco, L. A. Unpacking multimethodology: Impacts of a community development intervention. European Journal of Operational Research (2016) http://dx.doi.org/10.1016/j.ejor.2016.02.044

Figure 2: An extract of the group causal map.

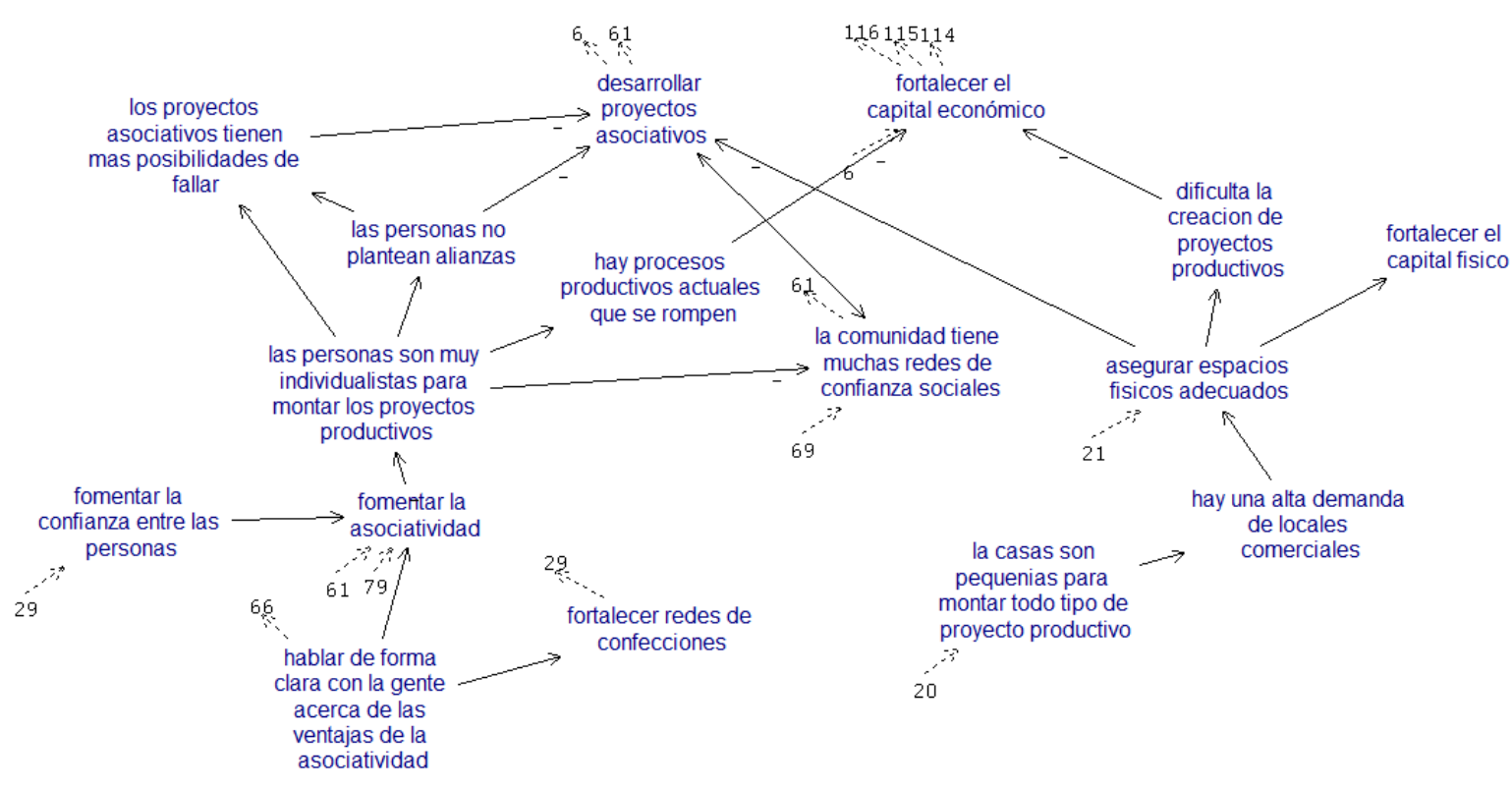


Please cite this article as:

Henao, F., \& Franco, L. A. Unpacking multimethodology: Impacts of a community development intervention.

European Journal of Operational Research (2016) http://dx.doi.org/10.1016/j.ejor.2016.02.044

Figure 3: Use of SSM methods and tools to operationalise a candidate business idea.

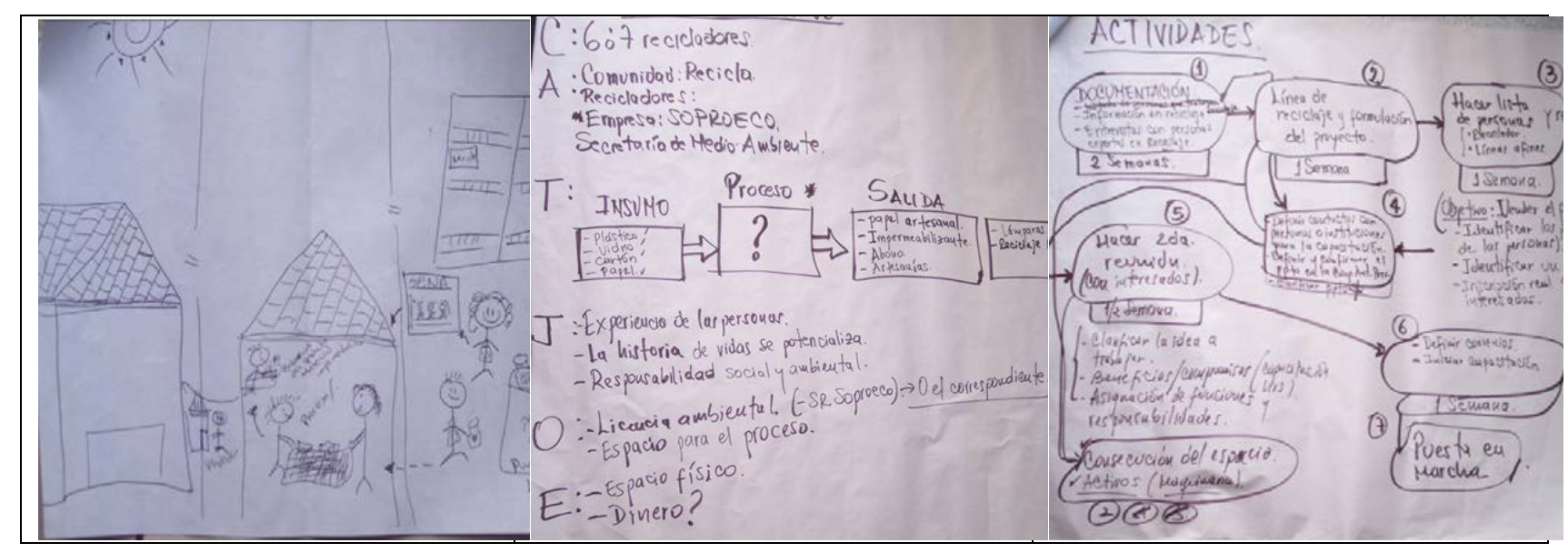


Please cite this article as:

Henao, F., \& Franco, L. A. Unpacking multimethodology: Impacts of a community development intervention. European Journal of Operational Research (2016) http://dx.doi.org/10.1016/j.ejor.2016.02.044

Figure 4: An extract of the MCDA model used at the decision conferencing workshop to evaluate the benefits and impacts of candidate business ideas

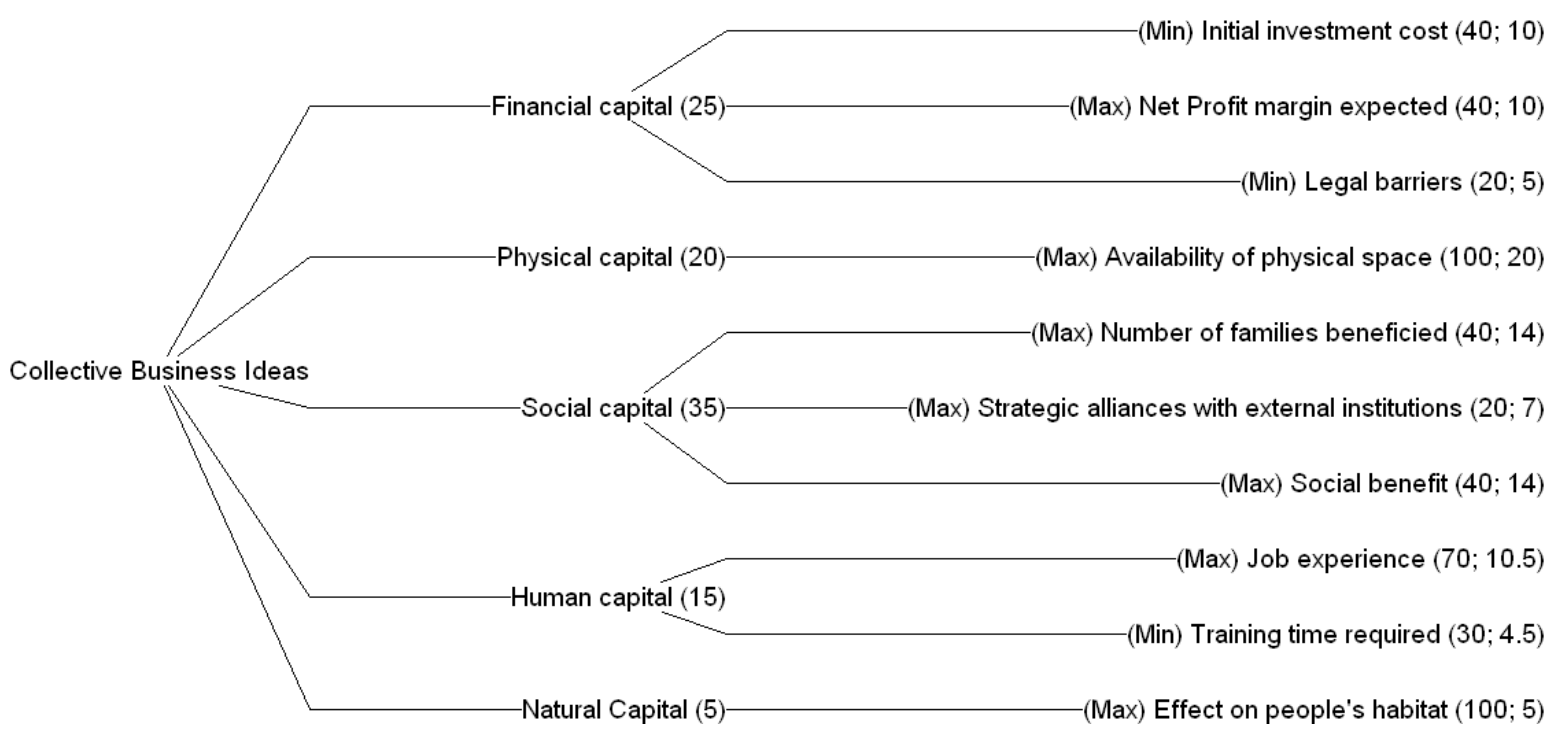

(a) Value tree.

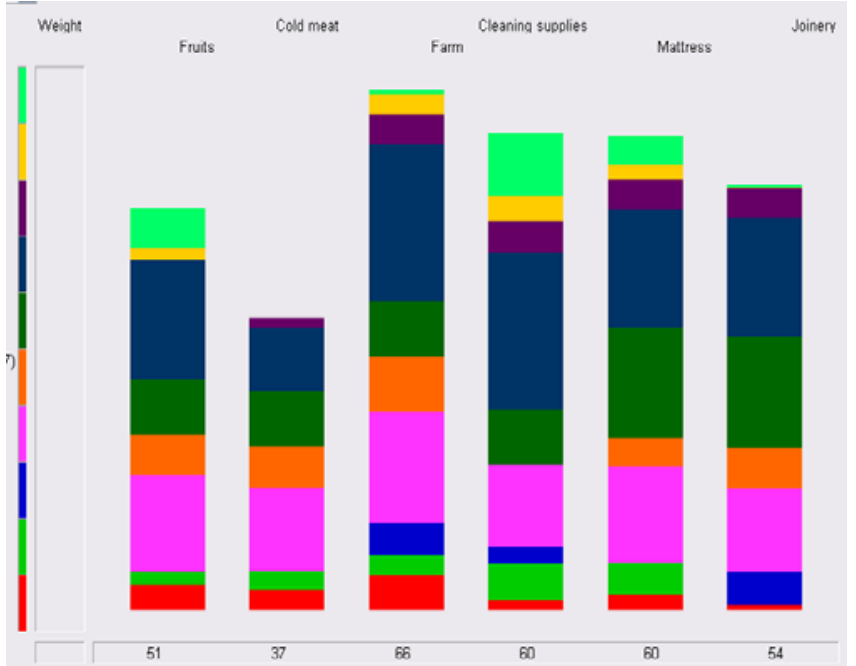

(b) Global score of business options in HiView.

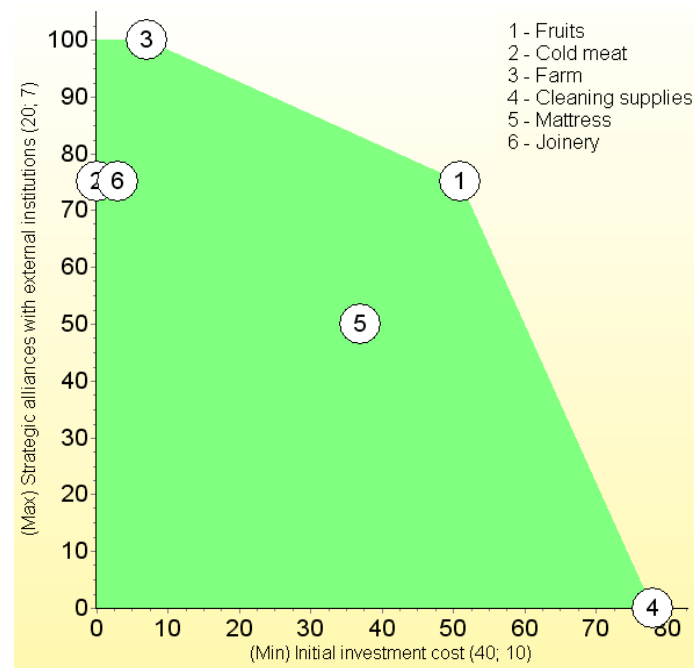

(c) Mapping benefits vs costs of options. 
Please cite this article as:

Henao, F., \& Franco, L. A. Unpacking multimethodology: Impacts of a community development intervention.

European Journal of Operational Research (2016) http://dx.doi.org/10.1016/j.ejor.2016.02.044

Figure 5: Four of the single family business ideas implemented

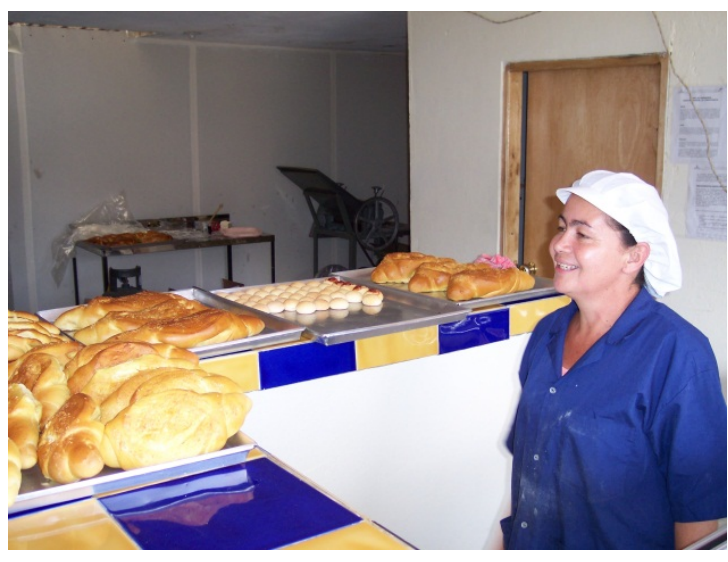

(a) Bakery

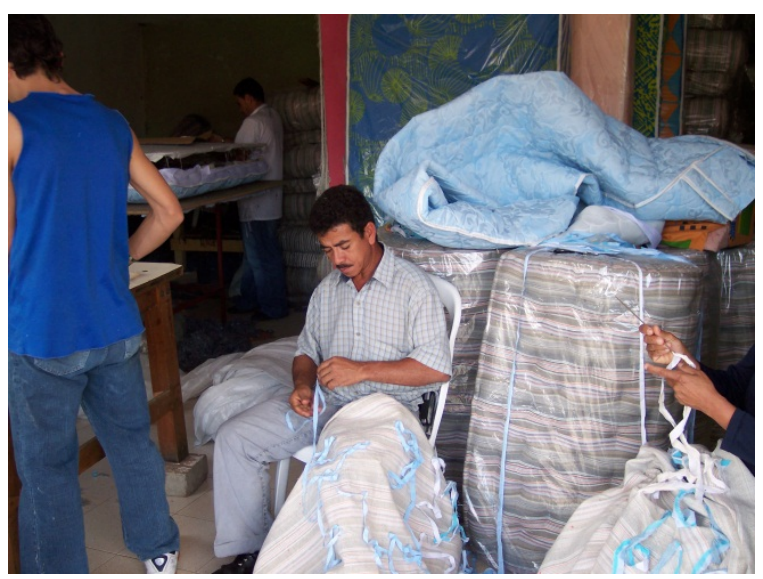

(c) Mattress factory

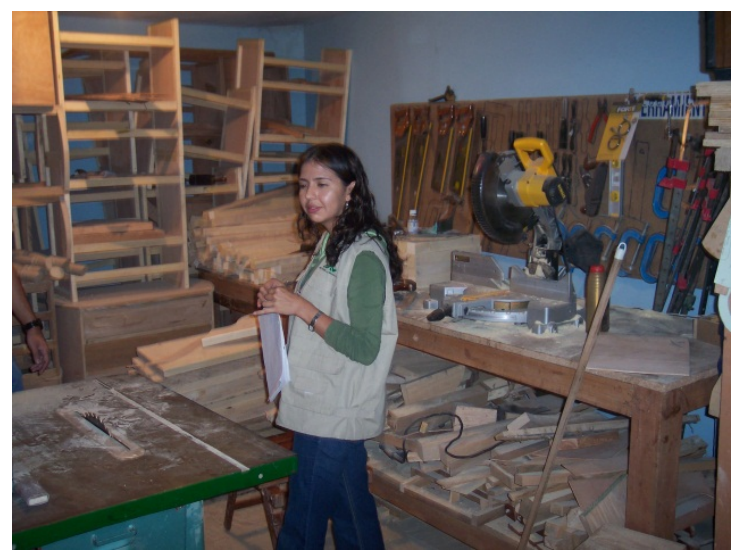

(b) Joinery

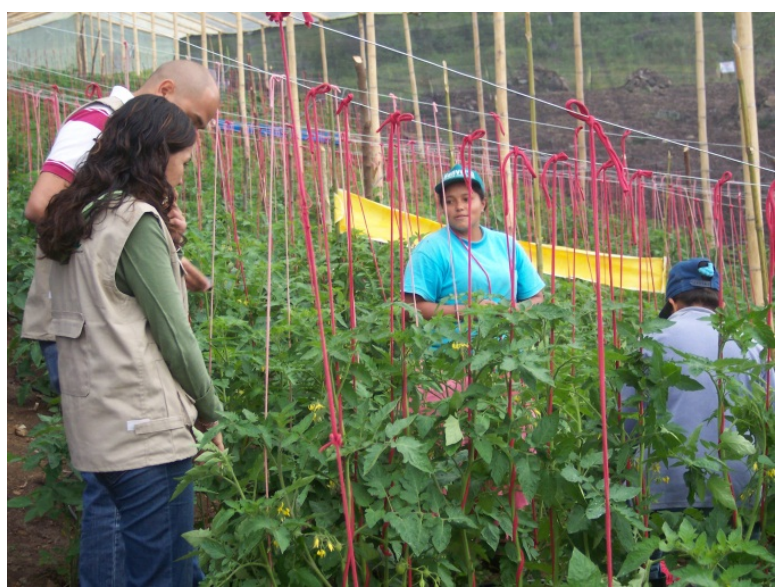

(d) Farm 
Please cite this article as:

Henao, F., \& Franco, L. A. Unpacking multimethodology: Impacts of a community development intervention. European Journal of Operational Research (2016) http://dx.doi.org/10.1016/j.ejor.2016.02.044

Figure 6: Data structure

$$
\begin{gathered}
1^{5 t} \text { order } \\
\text { categories }
\end{gathered}
$$

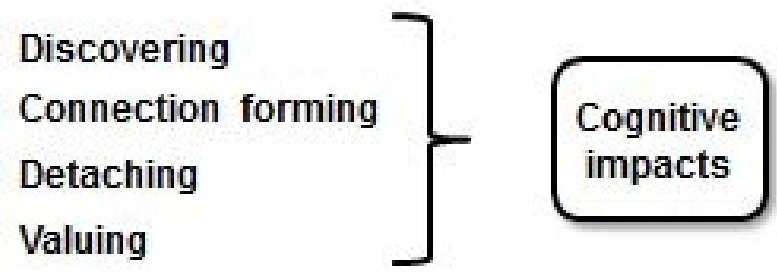

Funnelling

Case building
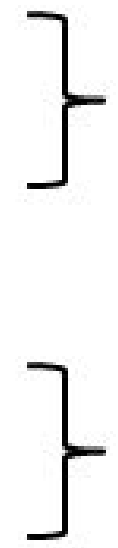

$$
2^{\text {nd }} \text { order }
$$

categories

\section{Cognitive}

impacts
Minding

Relational

Bonding

impacts 
Figure 7: Grounded process model of multimethodology intervention impacts

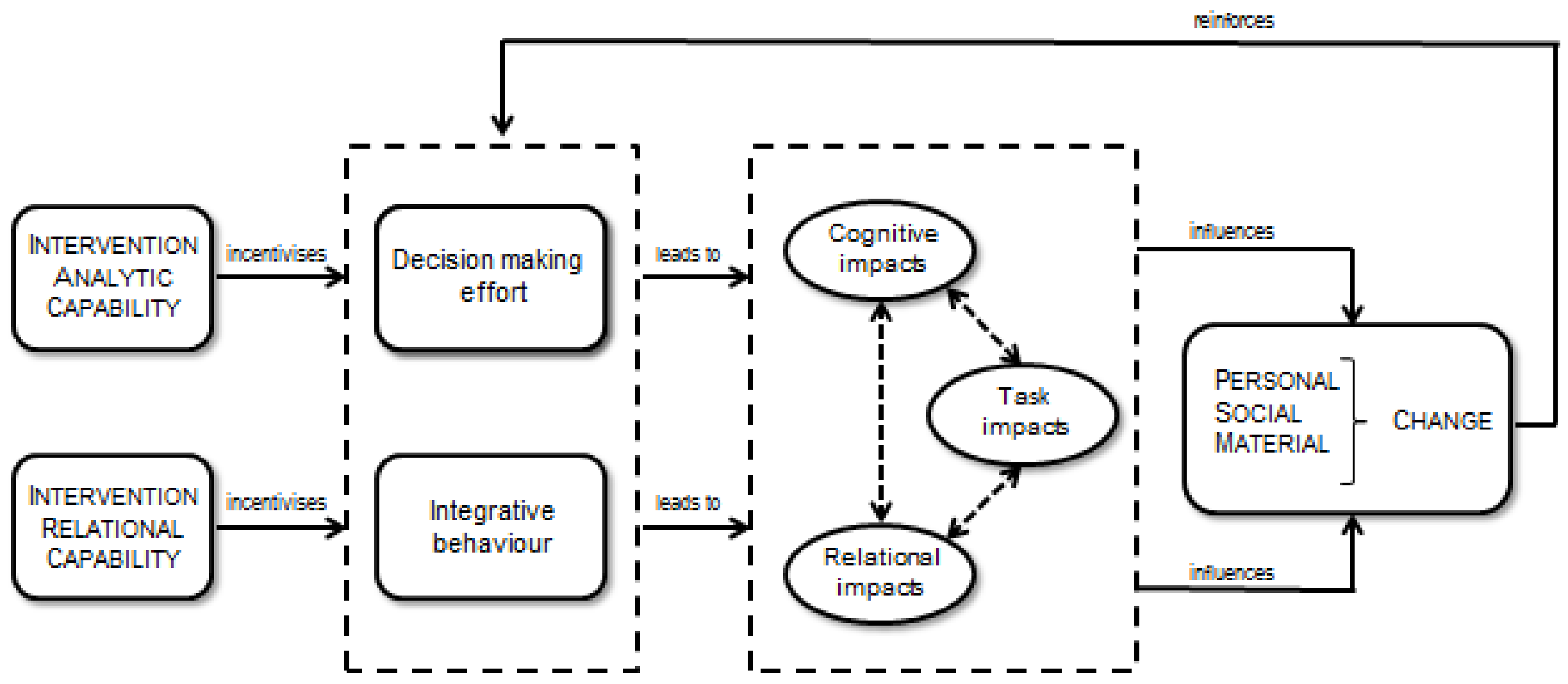

